\title{
Development of SCAR markers for rapid and specific detection of Pseudomonas syringae pv. morsprunorum races 1 and 2, using conventional and real-time PCR
}

\author{
Monika Kałużna $^{1}$ - Pedro Albuquerque ${ }^{2,3}$ - Fernando Tavares ${ }^{2,3}$. \\ Piotr Sobiczewski ${ }^{1}$. Joanna Puławska ${ }^{1}$
}

Received: 21 October 2015 /Revised: 16 December 2015 / Accepted: 26 December 2015 / Published online: 1 February 2016

(C) The Author(s) 2016. This article is published with open access at Springerlink.com

\begin{abstract}
Specific primers were developed to detect the causal agent of stone fruit bacterial canker using conventional and real-time polymerase chain reaction (PCR) methods. PCR melting profile (PCR MP) used for analysis of diversity of Pseudomonas syringae strains, allowed to pinpoint the amplified fragments specific for $P$. syringae pv. morsprunorum race $1\left(P_{s m} 1\right)$ and race 2 ( $\left.P_{s m} 2\right)$, which were sequenced. Using obtained data, specific sequence characterised amplified region (SCAR) primers were designed. Conventional and realtime PCRs, using genomic DNA isolated from different bacterial strains belonging to the Pseudomonas genus, confirmed the specificity of selected primers. Additionally, the specificity of the selected DNA regions for Psm 1 and Psm2 was confirmed by dot blot hybridisation. Conventional and real-time PCR assays enabled accurate detection of Psm 1 and Psm2 in pure cultures and in plant material. For conventional PCR, the detection limits were the order of magnitude $\sim 10^{\circ} \mathrm{cfu} /$ reaction for $P s m 1$ and $10^{1} \mathrm{cfu} /$ reaction for $P s m 2$ in pure cultures, while in plant material were $10^{0}-10^{1} \mathrm{cfu} /$ reaction using primers for $P s m 1$ and $3 \times 10^{2}$ cfu/reaction using primers for Psm2. Realtime PCR assays with SYBR Green I showed a higher limit of detection (LOD) $-10^{\circ} \mathrm{cfu} /$ reaction in both pure culture and in
\end{abstract}

Monika Kałużna

monika.kaluzna@inhort.pl

1 Research Institute of Horticulture, Konstytucji 3 Maja 1/3, 96-100 Skierniewice, Poland

2 Centro de Investigação em Biodiversidade e Recursos Genéticos (CIBIO), InBIO, Laboratório Associado, Universidade do Porto, Campus Agrário de Vairão, 4485-661 Vairão, Portugal

3 Faculdade de Ciencias, Departamento de Biologia, Universidade do Porto, Edifício FC4, Via Panoramica No. 36,

4150-564 Porto, Portugal plant material for each primer pairs designed, which corresponds to 30-100 and 10-50 fg of DNA of Psm 1 and Psm2, respectively. To our knowledge, this is the first PCR-based method for detection of the causal agents of bacterial canker of stone fruit trees.

Keywords Dotblothybridisation - Stone fruit tree pathogens · PCR MP · SCAR primers $\cdot$ Real-time PCR

\section{Introduction}

Bacterial canker of fruit trees occurs in stone fruit growing areas all over the world (Agrios 2005). In Poland, the disease incidence on stone fruit trees orchards is observed every year with different intensity and is becoming more economically significant. Moreover, in the last vegetative seasons, bacterial canker was dangerous not only to stone fruit trees, but also to apple and pear trees. The causal agents of the disease belong to the polyphagous Pseudomonas syringae species, able to infect more than 180 plant species, both annual and perennial, including fruit trees, ornamental plants and vegetables. P. syringae affects all organs of the aboveground parts of trees (i.e. the branches and main trunk as well as buds, blossoms, leaves and fruits), which causes reduction of yield and sometimes leads to death of the trees.

P. syringae is composed of plant pathogens divided into 60 pathovars (Young 2010) belonging to nine genomospecies, as determined by DNA:DNA hybridisation (Gardan et al. 1999). On King's B medium, the majority of these bacteria produce a fluorescent pigment visible under UV light (King et al. 1954). Bacteria that cause bacterial canker on stone fruit trees belong to three genomospecies (gs): gs $1-P$. syringae pv. syringae (Pss); gs $2-P$. syringae pv. morsprunorum race 1 (Psm 1$)$; and gs 3-P. syringae pv. morsprunorum race 2 (Psm2), 
P. syringae pv. avii ( $P s a)$ and $P$. syringae pv. persicae $(P s p)$ (reviewed in Bultreys and Kałużna 2010). In Poland, three taxa were already described as present: Pss, Psm 1 and $P s m 2$. Recently, the new atypical taxon including bacteria that infect only cherries (mainly sour cherry) was also found (Kałużna data not published).

The diagnostics of bacterial canker are commonly based on isolation and phenotypic characterisation of the causal agent, including pathogenicity (Bultreys and Gheysen 1999; Vicente et al. 2004). The phenotypic tests LOPAT (Lelliott et al. 1966), GATTa and L-lactate utilisation (Lattore and Jones 1979) enable the determination of morphological, physiological and biochemical features of the bacteria. These features are used for identification of species and their discrimination into pathovars and races. However, this methodology requires the implementation of a high number of often laborious and time-consuming tests. Moreover, the obtained results can sometimes be ambiguous or difficult to interpret, and they are often not sufficient for proper strain classification (Vicente et al. 2004).

Concerning serological methods, the slide agglutination test, immunofluorescence and indirect-enzyme-linked immunosorbent assay (ELISA), with the antisera produced from live whole-cell antigens, were widely adopted for routine bacterial identification. However, nowadays these methods are less frequently used for the identification of bacteria that cause bacterial canker because of frequent cross-reactions with nonpathogenic bacteria. Furthermore, serological tests do not always provide a response in distinguishing isolates of P. syringae (Vicente et al. 2004).

Molecular methods are currently the most widely adapted and are considered very useful for the identification of bacterial canker causal agents and for studying their genetic diversity. For many years, the identification of the pathogen has been based on detection of genes encoding the toxins coronatine, syringomycin and the siderophore yersiniabactin (Bereswill et al. 1994; Sorensen et al. 1998; Bultreys and Gheysen 1999). However, it should be noted that the determination of presence of genes encoding for toxin production is not reliable for identification in itself and thus cannot be the only criterion for the classification of strains. In fact, strains of Psm 1 and Pss, which do not have the ability to produce coronatine or syringomycin, respectively, are quite common (Ullrich et al. 1993; Renick et al. 2008; Kałużna et al. 2010a). On the other hand, although production of the siderophore yersiniabactin is now considered a stable feature of all Psm2 strains and could be a criterion for their identification, is should be mentioned that it is not an exclusive feature of strains of Psm2, since positive amplification with primers for the irp 1 gene (encoding this siderophore) was also confirmed in other pathovars of $P$. syringae, including the following: antirrhini, apii, berberidis, delphinii, lachrymans, passiflorae, persicae, tomato, viburni, helianthi, tagetis and theae (Bultreys et al. 2006).

In recent years, fingerprinting methods have been widely applied for the identification and genotyping of $P$. syringae through the analysis of repetitive regions (i.e. Enterobacterial Repetitive Intergenic Consensus (ERIC), BOX, Repetitive Extragenic Palindromic Elements (REP) and Insertion Sequence (IS50) sequences) (Ullrich et al. 1993; Weingart and Völksch 1997) and through PCR MP (Kałużna et al. 2010b). However, it should be taken into account that all fingerprinting methods require inclusion of the reference strains for comparison of obtained amplification patterns (Vicente and Roberts 2007; Gilbert et al. 2009), and, in the case of heterogeneous strains of PSS (Vicente et al. 2004; Renick et al. 2008; Kałużna et al. 2010a, b), it is difficult to determine affiliation of analysed strains to this taxon.

Despite the availability of different approaches for characterisation and genotyping of $P$. syringae, they require timeconsuming and labour-intensive classical microbiological methods or complex analyses including comparison of amplification patterns and housekeeping gene sequencing. Therefore, there is still the need to develop a rapid and specific method of diagnosis that would allow the detection and identification of the causal agent of stone fruit bacterial canker (López et al. 2010). This specific, fast diagnostic system would be invaluable in the study on etiology of cankers on trunks and branches, which are similar to those caused by fungi of the genus Leucostoma (Valsa) and Monilinia, and also necrotic spots on leaves, which may be mistaken with those caused by Prunus necrotic ring spot virus or Clasterosporium carpophilum, especially late in the growing season. Moreover, the occurrence of gummosis on woody tissue often associated with bacterial infection may be related to the physiological response of the trees to damage caused by abiotic factors, such as frost, sunburn, periodic water flooding or mechanical damage, and is not due to biotic factors only (Saniewski et al. 2006).

Ideally, a novel diagnostic system would apply specific primers and the PCR technique, both conventional and real-time, making them more useful for a wide group of researchers according to available lab equipment, which allows for the detection and identification of the pathogen within a short amount of time. Additionally, such a system would undoubtedly be very useful in enforcing appropriate programmes to prevent and control disease occurrence in nurseries and orchards of stone fruit trees, especially sweet and sour cherry, where the damage is the most severe.

The aim of this study was to design and validate novel specific primers and to develop conventional and real-time PCR-based methodologies for rapid and specific detection of $P s m 1$ and Psm2, with the aim of enhancing bacterial canker diagnostic procedures. 


\section{Materials and methods}

\section{Bacterial strains}

Species and pathovar identification of previously uncharacterised Pseudomonas strains from our collection, obtained from stone fruit trees in Poland, was determined on the basis of phenotypic tests (i.e. Gram reaction with $3 \% \mathrm{KOH}$ (Suslow et al. 1982), LOPAT (Lelliott et al. 1966), GATTa and L-lactate utilisation (Lattore and Jones 1979). A total of 168 isolates were analysed. The reference strains P. syringae pv. syringae-LMG 1247 , P. syringae pv. morsprunorum race $1-\mathrm{LMG} 2222$ and $P$. syringae pv. morsprunorum race 2-CFBP 3800 were included in all tests (Table 1). Additionally, type and not-type strains of other P. syringae pathovars (79) and related species (three) were included in the analysis (Table 2). The strains were kept at $-75{ }^{\circ} \mathrm{C}$ in a mixture of glycerol $(200 \mu \mathrm{l} / \mathrm{ml})$ and phosphate-buffered saline (PBS) and streaked on King's B medium (3.8 \% Pseudomonas Agar F Difco, $1 \%$ glycerol) (King et al. 1954) for routine culturing.

\section{DNA isolation}

Bacterial DNA was isolated using the method described by Aljanabi and Martinez (1997), with slight modifications described by Kałużna et al. (2012). DNA was diluted to a final concentration of $10 \mathrm{ng} / \mu \mathrm{l}$ and kept at $-20{ }^{\circ} \mathrm{C}$ for further analysis.

\section{PCR melting profile}

A slightly modified method of PCR MP described by Masny and Płucienniczak (2003) was used. An amount of $100 \mathrm{ng}$ of DNA from 23 Pseudomonas strains (Figs. 1 and 2) was digested with Pst $\mathrm{I}$ endonuclease $(10 \mathrm{U} / \mu \mathrm{l}$; Promega

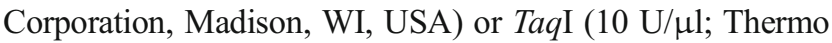
Scientific, Vilnius, Lithuania) according to the manufacturer's instructions. Digested DNA was ligated with two oligonucleotides forming an adaptor: DNA digested by PstI endonuclease with a PstI adaptor-5'-TGTACGCAGTCTAC-3'/5'CTCGTAGACTGCGTACATGCA-3' (Waugh et al. 1997) and DNA digested by TaqI endonuclease with a TaqI adapt o r - 5' - G A C G A T G A G T C C T G A C - 3'/ $5^{\prime}$ CGGTCAGGACTCAT-3' (Ajmone-Marsan et al. 1997). PCR amplification was performed separately for PstI- or TaqIdigested DNA in a 25- $\mu$ l reaction mixture containing the following: $1 \mu \mathrm{l}$ of ligation mixture; $0.4 \mathrm{U}$ of GoTaq DNA polymerase (Promega, Madison, WI, USA) for Pst $\mathrm{I}$ and $0.4 \mathrm{U}$ of Dream Taq Green DNA Polymerase (Thermo Scientific, Vilnius, Lithuania) for TaqI; and 1× of appropriate Taq polymerase buffer, $0.2 \mathrm{mM}$ of dNTPs and $1 \mu \mathrm{M}$ of each primer
(PstI-0-5'-GACTGCGTACATGCAG-3' for Pst Idigested DNA (Waugh et al. 1997) or TaqI-0 - 5'GACGATGAGTCCTGACCGA-3' for TaqI-digested DNA (Ajmone-Marsan et al. 1997)). The amplification reactions were conducted in a Biometra T3000 thermocycler (Biometra, Göttingen, Germany) with the following conditions: initial step of $72{ }^{\circ} \mathrm{C}$ for $5 \mathrm{~min}$; 30 cycles at $86.5{ }^{\circ} \mathrm{C}$ for PstI and $83{ }^{\circ} \mathrm{C}$ for TaqI for $40 \mathrm{~s}$, $55{ }^{\circ} \mathrm{C}$ for $40 \mathrm{~s}$ and extension at $72{ }^{\circ} \mathrm{C}$ for $90 \mathrm{~s}$; and final extension at $72{ }^{\circ} \mathrm{C}$ for $10 \mathrm{~min}$. PCR products from each reaction and the O'GeneRuler 100-bp DNA Ladder Plus (Thermo Scientific, Vilnius, Lithuania) were separated on a $1.5 \%$ agarose gel in $0.5 \times$ TBE buffer (0.045 M tris-boric acid, 0.001 M EDTA, pH 8.0) and electrophoresis was ran at 5-7 V/cm of gel. After staining with an ethidium bromide solution $(0.5 \mu \mathrm{g} / \mathrm{ml})$, the obtained amplification profiles were visualised under UV light. The same conditions were used in all subsequent electrophoresis.

\section{Selection of specific fragments}

Based on the results of genetic analyses using PCR MP, DNA fragments characteristic of Psm 1 and Psm 2 strains were selected. The fragments were excised from the gel, purified with the DNA AxyPrep Gel Extraction Kit (Axygen Scientific, Inc. Union City, CA, USA) and cloned into the pGEM T-Easy vector (Promega, Madison, WI, USA) according to the manufacturer's instructions. The resulting ligation mixture was used to transform Escherichia coli JM109 competent cells (Promega, Madison, WI, USA). The cloned fragments were sequenced with universal primers M13Rev 5'CAGGAAACAGCTATGAC- $3^{\prime}$ and M13 (-40) 5'GTTTTCCCAGTCACGAC-3' at Genomed S.A. (Warsaw, Poland). The sequences obtained were assembled using the SeqMan software package LASERGENE (DNASTAR, Madison, USA).

\section{Design of SCAR primers}

The sequences of specific fragments for Psm 1 and Psm2 were used to design the SCAR primers, for both conventional and real-time PCR, with the PrimerSelect programme of the LASERGENE package (DNASTAR). Different primer pairs were designed for conventional PCR (five for Psm 1 and 7 for Psm2) and real time PCR (four for each taxa). All primer sequences and their potential amplification reaction products were checked for homology (June 2015) to other sequences deposited in the GenBank database using the 'blastn' algorithm (Altschul et al. 1997). Selected primers were synthesised at Genomed S.A. 
Table 1 Strains of $P$. syringae used in this study

\begin{tabular}{|c|c|c|c|c|c|}
\hline Lp. & Strain number & $\begin{array}{l}\text { Place (voivodeship/country) } \\
\text { and year of isolation }\end{array}$ & & Host-plant & $\begin{array}{l}\text { Taxon based on } \\
\text { LOPAT, GATTa/L }\end{array}$ \\
\hline 1. & 58 & Łódzkie, PL & 2007 & Sour cherry & Atypical taxon \\
\hline 2. & 59 & Łódzkie, PL & 2007 & Sour cherry & Atypical taxon \\
\hline 3. & 61 & Łódzkie, PL & 2007 & Sour cherry & Atypical taxon \\
\hline 4. & 64 & Łódzkie, PL & 2007 & Sour cherry & Atypical taxon \\
\hline 5. & 65 & Łódzkie, PL & 2007 & Sour cherry & Atypical taxon \\
\hline 6. & 66 & Łódzkie, PL & 2007 & Sour cherry & Atypical taxon \\
\hline 7. & 69 & Łódzkie, PL & 2007 & Sour cherry & Atypical taxon \\
\hline 8. & 71 & Łódzkie, PL & 2007 & Sour cherry & Atypical taxon \\
\hline 9. & 72 & Łódzkie, PL & 2007 & Sour cherry & Atypical taxon \\
\hline 10. & 73 & Łódzkie, PL & 2007 & Sour cherry & Atypical taxon \\
\hline 11. & 74 & Łódzkie, PL & 2007 & Sour cherry & Atypical taxon \\
\hline 12. & 75 & Łódzkie, PL & 2007 & Sour cherry & Atypical taxon \\
\hline 13. & 76 & Łódzkie, PL & 2007 & Sour cherry & Atypical taxon \\
\hline 14. & 78 & Łódzkie, PL & 2007 & Sour cherry & Atypical taxon \\
\hline 15. & 80 & Łódzkie, PL & 2007 & Sour cherry & Atypical taxon \\
\hline 16. & 81 & Łódzkie, PL & 2007 & Sour cherry & Atypical taxon \\
\hline 17. & 82 & Łódzkie, PL & 2007 & Sour cherry & Atypical taxon \\
\hline 18. & 83 & Łódzkie, PL & 2007 & Sour cherry & Atypical taxon \\
\hline 19. & 86 & Łódzkie, PL & 2007 & Sour cherry & Atypical taxon \\
\hline 20. & 87 & Łódzkie, PL & 2007 & Sour cherry & Atypical taxon \\
\hline 21. & 88 & Łódzkie, PL & 2007 & Sour cherry & Atypical taxon \\
\hline 22. & 89 & Łódzkie, PL & 2007 & Sour cherry & Atypical taxon \\
\hline 23. & 90 & Łódzkie, PL & 2007 & Sour cherry & Atypical taxon \\
\hline 24. & 91 & Łódzkie, PL & 2007 & Sour cherry & Atypical taxon \\
\hline 25. & 93 & Łódzkie, PL & 2007 & Sour cherry & Atypical taxon \\
\hline 26. & 94 & Łódzkie, PL & 2007 & Sour cherry & Atypical taxon \\
\hline 27. & 95 & Łódzkie, PL & 2007 & Sour cherry & Atypical taxon \\
\hline 28. & 96 & Łódzkie, PL & 2007 & Sour cherry & Atypical taxon \\
\hline 29. & 118 & Mazowieckie, PL & 2007 & Sour cherry & Atypical taxon \\
\hline 30. & 119 & Mazowieckie, PL & 2007 & Sour cherry & Atypical taxon \\
\hline 31. & 120 & Łódzkie, PL & 2007 & Sour cherry & Atypical taxon \\
\hline 32. & 122 & Łódzkie, PL & 2007 & Sour cherry & Atypical taxon \\
\hline 33. & 211 & Łódzkie, PL & 2007 & Sour cherry & Atypical taxon \\
\hline 34. & 271 & Silesian, PL & 2007 & Sour cherry & Atypical taxon \\
\hline 35. & 374 & Łódzkie, PL & 2008 & Sour cherry & Atypical taxon \\
\hline 36. & 439 & Łódzkie, PL & 2008 & Sour cherry & Atypical taxon \\
\hline 37. & 909 & Łódzkie, PL & 2009 & Sour cherry & Atypical taxon \\
\hline 38. & 910 & Łódzkie, PL & 2009 & Sour cherry & Atypical taxon \\
\hline 39. & 949 & Łódzkie, PL & 2009 & Sour cherry & Atypical taxon \\
\hline 40. & 963 & Lubelskie, PL & 2009 & Sweet cherry & Atypical taxon \\
\hline 41. & 966 & Lubelskie, PL & 2009 & Sour cherry & Atypical taxon \\
\hline 42. & 967 & Lubelskie, PL & 2009 & Sour cherry & Atypical taxon \\
\hline 43. & 968 & Lubelskie, PL & 2009 & Sour cherry & Atypical taxon \\
\hline 44. & $969 a$ & Lubelskie, PL & 2009 & Sour cherry & Atypical taxon \\
\hline 45. & $969 b$ & Lubelskie, PL & 2009 & Sour cherry & Atypical taxon \\
\hline 46. & $970 \mathrm{a}$ & Lubelskie, PL & 2009 & Sour cherry & Atypical taxon \\
\hline 47. & $970 \mathrm{~b}$ & Lubelskie, PL & 2009 & Sour cherry & Atypical taxon \\
\hline 48. & $971 \mathrm{a}$ & Lubelskie, PL & 2009 & Sour cherry & Atypical taxon \\
\hline
\end{tabular}


Table 1 (continued)

\begin{tabular}{|c|c|c|c|c|c|}
\hline Lp. & Strain number & $\begin{array}{l}\text { Place (voivodeship/country) } \\
\text { and year of isolation }\end{array}$ & & Host-plant & $\begin{array}{l}\text { Taxon based on } \\
\text { LOPAT, GATTa/L }\end{array}$ \\
\hline 49. & $971 b$ & Lubelskie, PL & 2009 & Sour cherry & Atypical taxon \\
\hline 50. & 972 & Lubelskie, PL & 2009 & Sour cherry & Atypical taxon \\
\hline 51. & 973 & Lubelskie, PL & 2009 & Sour cherry & Atypical taxon \\
\hline 52. & 981 & Lubelskie, PL & 2009 & Sour cherry & Atypical taxon \\
\hline 53. & 982 & Lubelskie, PL & 2009 & Sour cherry & Atypical taxon \\
\hline 54. & 1017 & Łódzkie, PL & 2009 & Sour cherry & Atypical taxon \\
\hline 55. & 1021 & Łódzkie, PL & 2009 & Sour cherry & Atypical taxon \\
\hline 56. & 791 & No data & 2001 & Sour cherry & Atypical taxon \\
\hline 57. & 441 & Łódzkie, PL & 2008 & Plum & Psm 1 \\
\hline 58. & LMG 2222 & No data, UK & 1958 & Prunus avium & Psm 1 \\
\hline 59. & $25 \mathrm{~b}$ & Łódzkie, PL & 2007 & Sweet cherry & Psm 1 \\
\hline 60. & $28 \mathrm{a}$ & Łódzkie, PL & 2007 & Sweet cherry & Psm 1 \\
\hline 61. & $29 \mathrm{a}$ & Łódzkie, PL & 2007 & Sweet cherry & Psm 1 \\
\hline 62. & $38 \mathrm{a}$ & Łódzkie, PL & 2007 & Plum & Psm 1 \\
\hline 63. & 98 & Łódzkie, PL & 2007 & Sweet cherry & $\operatorname{Psm} 1$ \\
\hline 64. & 100 & Łódzkie, PL & 2007 & Plum & Psm 1 \\
\hline 65. & 107 & Łódzkie, PL & 2007 & Plum & Psm 1 \\
\hline 66. & 158 & West Pomerania, PL & 2007 & Sweet cherry & Psm 1 \\
\hline 67. & 174 & West Pomerania, PL & 2007 & Sweet cherry & Psm 1 \\
\hline 68. & 175 & West Pomerania, PL & 2007 & Sweet cherry & Psm 1 \\
\hline 69. & 177 & West Pomerania, PL & 2007 & Peach & Psm 1 \\
\hline 70. & 199 & West Pomerania, PL & 2007 & Plum & $\operatorname{Psm} 1$ \\
\hline 71. & 201 & West Pomerania, PL & 2007 & Plum & Psm 1 \\
\hline 72. & 202 & West Pomerania, PL & 2007 & Plum & $\operatorname{Psm} 1$ \\
\hline 73. & 203 & West Pomerania, PL & 2007 & Plum & Psm 1 \\
\hline 74. & 204 & West Pomerania, PL & 2007 & Plum & Psm 1 \\
\hline 75. & 205 & West Pomerania, PL & 2007 & Plum & Psm 1 \\
\hline 76. & 206 & West Pomerania, PL & 2007 & plum & Psm 1 \\
\hline 77. & 209 & West Pomerania, PL & 2007 & Plum & Psm 1 \\
\hline 78. & 213 & Świętokrzyskie, PL & 2007 & Plum & Psm 1 \\
\hline 79. & 214 & Kuyavian-Pomeranian, PL & 2007 & Sweet cherry & Psm 1 \\
\hline 80. & 215 & Kuyavian-Pomeranian, PL & 2007 & Sweet cherry & $\operatorname{Psm} 1$ \\
\hline 81. & 216 & Kuyavian-Pomeranian, PL & 2007 & Sweet cherry & $\operatorname{Psm} 1$ \\
\hline 82. & 217 & Kuyavian-Pomeranian, PL & 2007 & Sweet cherry & $\operatorname{Psm} 1$ \\
\hline 83. & 218 & Kuyavian-Pomeranian, PL & 2007 & Sweet cherry & $\operatorname{Psm} 1$ \\
\hline 84. & 219 & Kuyavian-Pomeranian, PL & 2007 & Sweet cherry & $\operatorname{Psm} 1$ \\
\hline 85. & 220 & Kuyavian-Pomeranian, PL & 2007 & Plum & $\operatorname{Psm} 1$ \\
\hline 86. & 221 & Kuyavian-Pomeranian, PL & 2007 & Plum & $\operatorname{Psm} 1$ \\
\hline 87. & 250 & Kuyavian-Pomeranian, PL & 2007 & Plum & Psm 1 \\
\hline 88. & 274 & Silesian, PL & 2007 & Plum & Psm 1 \\
\hline 89. & 276 & Silesian, PL & 2007 & Plum & Psm 1 \\
\hline 90. & 280 & Silesian, PL & 2007 & Plum & Psm 1 \\
\hline 91. & 283 & Silesian, PL & 2007 & Sweet cherry & Psm 1 \\
\hline 92. & 291 & Łódzkie, PL & 2007 & Sweet cherry & Psm 1 \\
\hline 93. & 527 & Mazowieckie, PL & 2008 & Sweet cherry & Psm 1 \\
\hline 94. & 528 & Mazowieckie, PL & 2008 & Sweet cherry & Psm 1 \\
\hline 95. & 671 & Lubelskie, PL & 2008 & Sweet cherry & Psm 1 \\
\hline 96. & 1061 & Łódzkie, PL & 2009 & Plum & $P s m 1$ \\
\hline
\end{tabular}


Table 1 (continued)

\begin{tabular}{|c|c|c|c|c|c|}
\hline Lp. & Strain number & $\begin{array}{l}\text { Place (voivodeship/country) } \\
\text { and year of isolation }\end{array}$ & & Host-plant & $\begin{array}{l}\text { Taxon based on } \\
\text { LOPAT, GATTa/L }\end{array}$ \\
\hline 97. & $701 \mathrm{~A}$ & No data, PL & 2005 & Sweet cherry & Psm 1 \\
\hline 98. & 702 & No data, PL & 1994 & Plum & Psm 1 \\
\hline 99. & 704 & No data, PL & 1994 & Sweet cherry & Psm 1 \\
\hline 100. & 710 & Lower Silesian, PL & 1996 & Sweet cherry & Psm 1 \\
\hline 101. & 755 & No data, PL & 1999 & Plum & Psm 1 \\
\hline 102. & 771 & Łódzkie, PL & 1999 & Plum & Psm 1 \\
\hline 103. & 782 & No data, PL & 2001 & Sweet cherry & Psm 1 \\
\hline 104. & 787 & Mazowieckie, PL & 2001 & Plum & Psm 1 \\
\hline 105. & 788 & Łódzkie, PL & 2001 & Plum & Psm 1 \\
\hline 106. & 793 & Łódzkie, PL & 2001 & Plum & Psm 1 \\
\hline 107. & CFBP 3800 & No data, UK & ND & Prunus cerasus & Psm2 \\
\hline 108. & 77 & Łódzkie, PL & 2007 & Sour cherry & Psm2 \\
\hline 109. & 117 & Mazowieckie, PL & 2007 & Sour cherry & Psm 2 \\
\hline 110. & 266 & Silesian, PL & 2007 & Sour cherry & Psm2 \\
\hline 111. & 417 & Mazowieckie, PL & 2008 & Sour cherry & Psm 2 \\
\hline 112. & 701 & No data, PL & 1994 & Sour cherry & Psm2 \\
\hline 113. & 719 & Łódzkie, PL & 1997 & Sour cherry & Psm2 \\
\hline 114. & 732 & Łódzkie, PL & 1997 & Sour cherry & Psm2 \\
\hline 115. & 733 & Łódzkie, PL & 1997 & Sour cherry & Psm2 \\
\hline 116. & 745 & Łódzkie, PL & 1999 & Sour cherry & Psm2 \\
\hline 117. & 764 & Mazowieckie, PL & 1999 & Sour cherry & Psm2 \\
\hline 118. & LMG 1247 & No data, UK & ND & Syringa vulgaris & Pss \\
\hline 119. & 2905 & No data/PL & 1978 & Sour cherry & Pss \\
\hline 120. & 68 & Łódzkie, PL & 2007 & Sour cherry & Pss \\
\hline 121. & 103 & Łódzkie, PL & 2007 & Sour cherry & Pss \\
\hline 122. & 106 & Łódzkie, PL & 2007 & Plum & Pss \\
\hline 123. & 109 & Łódzkie, PL & 2007 & Plum & Pss \\
\hline 124. & 110 & Łódzkie, PL & 2007 & Plum & Pss \\
\hline 125. & 112 & Łódzkie, PL & 2007 & Plum & Pss \\
\hline 126. & 115 & Łódzkie, PL & 2007 & Plum & Pss \\
\hline 127. & 141 & West Pomerania, PL & 2007 & Peach & Pss \\
\hline 128. & 147 & West Pomerania, PL & 2007 & Peach & Pss \\
\hline 129. & 165 & West Pomerania, PL & 2007 & Sweet cherry & Pss \\
\hline 130. & 184 & West Pomerania, PL & 2007 & Peach & Pss \\
\hline 131. & 192 & West Pomerania, PL & 2007 & Plum & Pss \\
\hline 132. & 210 & Łódzkie, PL & 2007 & Sour cherry & Pss \\
\hline 133. & 222 & Kuyavian-Pomeranian, PL & 2007 & Plum & Pss \\
\hline 134. & 226 & Kuyavian-Pomeranian, PL & 2007 & Plum & Pss \\
\hline 135. & 227 & Kuyavian-Pomeranian, PL & 2007 & Plum & Pss \\
\hline 136. & 229 & Kuyavian-Pomeranian, PL & 2007 & Plum & Pss \\
\hline 137. & 233 & Kuyavian-Pomeranian, PL & 2007 & Plum & Pss \\
\hline 138. & 234 & Kuyavian-Pomeranian, PL & 2007 & Plum & Pss \\
\hline 139. & 235 & Kuyavian-Pomeranian, PL & 2007 & Plum & Pss \\
\hline 140. & 236 & Kuyavian-Pomeranian, PL & 2007 & Plum & Pss \\
\hline 141. & 237 & Kuyavian-Pomeranian, PL & 2007 & Plum & Pss \\
\hline 142. & 239 & Kuyavian-Pomeranian, PL & 2007 & Plum & Pss \\
\hline 143. & 240 & Kuyavian-Pomeranian, PL & 2007 & Plum & Pss \\
\hline 144. & 242 & Kuyavian-Pomeranian, PL & 2007 & Plum & Pss \\
\hline
\end{tabular}


Table 1 (continued)

\begin{tabular}{|c|c|c|c|c|c|}
\hline Lp. & Strain number & $\begin{array}{l}\text { Place (voivodeship/country) } \\
\text { and year of isolation }\end{array}$ & & Host-plant & $\begin{array}{l}\text { Taxon based on } \\
\text { LOPAT, GATTa/L }\end{array}$ \\
\hline 145. & 244 & Kuyavian-Pomeranian, PL & 2007 & Plum & Pss \\
\hline 146. & 245 & Kuyavian-Pomeranian, PL & 2007 & Plum & Pss \\
\hline 147. & 247 & Kuyavian-Pomeranian, PL & 2007 & Plum & Pss \\
\hline 148. & 248 & Kuyavian-Pomeranian, PL & 2007 & Plum & Pss \\
\hline 149. & 256 & Kuyavian-Pomeranian, PL & 2007 & Plum & Pss \\
\hline 150. & 257 & Kuyavian-Pomeranian, PL & 2007 & Sour cherry & Pss \\
\hline 151. & 258 & Kuyavian-Pomeranian, PL & 2007 & Sour cherry & Pss \\
\hline 152. & 259 & Łódzkie, PL & 2007 & Sweet cherry & Pss \\
\hline 153. & 264 & Łódzkie, PL & 2007 & Peach & Pss \\
\hline 154. & 286 & Silesian, PL & 2007 & Sweet cherry & Pss \\
\hline 155. & 373 & Łódzkie, PL & 2008 & Sour cherry & Pss \\
\hline 156. & 376 & Łódzkie, PL & 2008 & Sour cherry & Pss \\
\hline 157. & 415 & Świętokrzyskie, PL & 2008 & Plum & Pss \\
\hline 158. & $420 \mathrm{a}$ & Mazowieckie, PL & 2008 & Sour cherry & Pss \\
\hline 159. & 435 & Mazowieckie, PL & 2008 & Sour cherry & Pss \\
\hline 160. & 437 & Łódzkie, PL & 2008 & Sour cherry & Pss \\
\hline 161. & 442 & Łódzkie, PL & 2008 & Plum & Pss \\
\hline 162. & 460 & Podkarpackie, PL & 2008 & Sour cherry & Pss \\
\hline 163. & 663 & Lubelskie, PL & 2008 & Sour cherry & Pss \\
\hline 164. & 914 & Kuyavian-Pomeranian, PL & 2009 & Sour cherry & Pss \\
\hline 165. & 959 & Lubelskie, PL & 2009 & Sour cherry & Pss \\
\hline 166. & $702 \mathrm{~A}$ & Łódzkie, PL & 2005 & Plum & Pss \\
\hline 167. & 753 & Łódzkie, PL & 1999 & Apricot & Pss \\
\hline 168. & 757 & Mazowieckie, PL & 1999 & Plum & Pss \\
\hline 169. & 760 & Mazowieckie, PL & 1999 & Sour cherry & Pss \\
\hline 170. & 762 & No data, PL & 1999 & Apricot & Pss \\
\hline 171. & 763 & No data, PL & 1999 & Sour cherry & Pss \\
\hline
\end{tabular}

LOPAT - levan production from sucrose $(L)$, presence of oxidase $(O)$, ability to cause rot on potato tubers ( $P$, pectolytic activity), presence of arginine dihydrolase $(A)$, hypersensitive reaction (HR) on tobacco plants; GATTA — gelatine hydrolysis $(G)$, aesculin hydrolysis $(A$, activity of the $\beta$-glucosidase), tyrosinase activity $(T)$, utilisation of tartrate $(T a)$; test of L-lactate utilisation $(L)$; PL Poland, $U K$ United Kingdom

\section{Dot blot hybridisation}

High-throughput specificity assays were carried out using a dot blot platform, essentially as previously described (Albuquerque et al. 2011). PCR amplicons obtained using primers Psm1-6F/6R, with template DNA from strain Psm 28a (race 1), and primers Psm2-8F/8R, with Psm 77 (race 2 ), were purified using the GFX PCR and Gel Band Purification Kit (GE Healthcare, Buckinghamshire, UK) and labelled with digoxigenin, using the DIG-High Prime DNA labelling kit (Roche, Basel, Switzerland) in order to obtain the two tested hybridisation probes Psm1 and Psm2, respectively.

Amounts of $100 \mathrm{ng}$ of heat-denatured DNA from each bacterial strain were transferred to a nylon membrane using a Bio-Dot apparatus (Bio-Rad, Hercules, USA). Hybridisation was carried out overnight at $68{ }^{\circ} \mathrm{C}$ with a final probe concentration of $100 \mathrm{ng} / \mathrm{mL}$, and the washing and detection steps were carried out according to the DIG application manual (Roche). The chemiluminescent signal indicative of probetarget hybrids was detected using a Molecular Imager ChemiDoc XRS+ System (Bio-Rad), with all pixels below saturation point.

\section{Conventional and real-time PCR amplifications}

Amplification reactions with the two selected primer pairs, one specific for the strains of $P s m 1$ and the second specific for $P s m 2$, were performed in a Biometra T3000 thermocycler (Biometra, Göttingen, Germany). The reaction mixture in $15 \mu$ l of total reaction volume contained $10 \mathrm{ng}$ of DNA, $0.4 \mathrm{U}$ of Dream DNA Polymerase (Promega, Madison, WI, USA), $1 \times$ reaction Dream Taq Green buffer (Thermo Scientific, Vilnius, Lithuania), $0.15 \mathrm{mM}$ dNTPs and $0.7 \mathrm{mM}$ of each primer. The following 
Table 2 Results of specificity of designed primers in reactions with DNA of different pathovars of Pseudomonas syringe and other Pseudomonas species tested

\begin{tabular}{|c|c|c|c|c|c|}
\hline $\begin{array}{l}\text { Pathovar of } \\
\text { P. syringae }\end{array}$ & $\begin{array}{l}\text { Strain } \\
\text { number* }\end{array}$ & Host & $\begin{array}{l}\text { Origin- } \\
\text { place/year of } \\
\text { isolation }\end{array}$ & $\begin{array}{l}\text { PCR result } \\
\text { with primers } \\
\text { Psm1-6F/6R } \\
\text { and Psm1- } \\
1 \mathrm{~F} / \mathrm{R}-\mathrm{RT} \\
\text { and Psm2- } \\
8 \mathrm{~F} / 8 \mathrm{R} \text { and } \\
\text { and Psm2- } \\
\text { 1F/1R-RT }\end{array}$ & $\begin{array}{c}\text { Reference/ } \\
\text { source }\end{array}$ \\
\hline aceris & CFBP $2339^{\mathrm{PT}}$ & Acer sp. & 1961 & $-* *$ & CFBP*** \\
\hline actinidiae & $\begin{array}{l}\text { CFBP } 4909^{\mathrm{PT}} \\
\text { MAFF } 302135 \\
\text { MAFF } 302145 \\
\text { MAFF } 613005\end{array}$ & $\begin{array}{l}\text { Actinidia deliciosa } \\
\text { Actinidia argute } \\
\text { Actinidia deliciosa } \\
\text { Actinidia deliciosa }\end{array}$ & \begin{tabular}{|l} 
Japan/1984 \\
Japan/1987 \\
Japan/1988 \\
Japan/1986
\end{tabular} & $\begin{array}{l}- \\
- \\
- \\
-\end{array}$ & $\begin{array}{l}\text { CFBP } \\
\text { MAFF } \\
\text { MAFF } \\
\text { MAFF }\end{array}$ \\
\hline aesculi & $\begin{array}{l}\text { CFBP 2894 } \\
6617 \\
2250 \\
\text { H3 } \\
\text { H4 } \\
2190\end{array}$ & $\begin{array}{l}\text { Aesculus indica } \\
\text { Aesculus hippocastanum } \\
\text { Aesculus hippocastanum } \\
\text { Aesculus hippocastanum } \\
\text { Aesculus hippocastanum } \\
\text { Aesculus hippocastanum }\end{array}$ & $\begin{array}{l}\text { India/1980 } \\
\mathrm{UK} / 2006 \\
\mathrm{UK} / 2008 \\
\text { Germany/2007 } \\
\text { Germany/2007 } \\
\text { UK }\end{array}$ & $\begin{array}{l}- \\
- \\
- \\
- \\
- \\
-\end{array}$ & $\begin{array}{l}\text { CFBP } \\
\text { R. W. W. } \\
\text { Jackson } \\
\text { (UK) } \\
]_{2008}^{\text {Schmidt }} \\
\text { et al., }\end{array}$ \\
\hline antirrhini & CFBP $1620^{\mathrm{PT}}$ & Antirrhinum majus & UK/1956 & - & CFBP \\
\hline apii & $\begin{array}{l}\text { CFBP } 2103^{\text {PT }} \\
\text { BS } 426 \\
\text { BS } 463\end{array}$ & $\begin{array}{l}\text { Apium graveolens } \\
\text { Petroselinum crispum } \\
\text { Flat-leaf parsley }\end{array}$ & $\begin{array}{l}\text { USA/1942 } \\
\text { USA/2003 } \\
\text { USA/2002 }\end{array}$ & $\begin{array}{l}- \\
- \\
-\end{array}$ & $\begin{array}{l}\text { CFBP } \\
\text { Bull et al. } \\
2011\end{array}$ \\
\hline aptata & CFBP $1617^{\mathrm{PT}}$ & Beta vulgaris & USA/1959 & - & CFBP \\
\hline atrofaciens & CFBP $2213^{\mathrm{PT}}$ & Triticum aestivum & $\begin{array}{l}\text { New } \\
\text { Zealand/1968 }\end{array}$ & - & CFBP \\
\hline atropurpurea & $\begin{array}{l}\text { CFBP } 2340^{\text {PT }} \\
1304\end{array}$ & Lolium multiflorum & $\mathrm{ND} / 1967$ & $\begin{array}{l}- \\
-\end{array}$ & $\begin{array}{l}\text { CFBP } \\
\text { K.Geider } \\
\text { (Germany) }\end{array}$ \\
\hline avii & CFBP $3846^{\mathrm{PT}}$ & Prunus avium & France/1991 & - & CFBP \\
\hline berberidis & CFBP $1727^{\mathrm{PT}}$ & Berberis sp. & $\begin{array}{l}\text { New } \\
\text { Zealand/1972 }\end{array}$ & - & CFBP \\
\hline broussonetiae & $\begin{array}{l}\text { CFBP } 5140^{\text {PT }} \\
\text { MAFF } 810038 \\
\text { MAFF } 810044\end{array}$ & $\begin{array}{lr}\text { Broussonetia } & \text { kazinoki } \\
\text { Sieb.X Broussonetia } \\
\text { papyrifa Vent. } \\
\text { Broussonetia } & \\
\text { Sieb. } & \\
\text { Brousinoki } \\
\text { Sieb. }\end{array}$ & $\begin{array}{l}\text { Japan/ } 1996 \\
\text { Japan/ } 1996\end{array}$ & - & $\begin{array}{l}\text { MAFF } \\
\text { MAFF }\end{array}$ \\
\hline castaneae & CFBP $4217^{\text {PT }}$ & Castanea crenata & Japan/1977 & - & CFBP \\
\hline cerasicola & CFBP $6109^{\mathrm{PT}}$ & Prunus Xyedoensis & Japan/1995 & - & CFBP \\
\hline ciccaronei & CFBP $2342^{\text {PT }}$ & Ceratonia siligua & Italy/1942 & - & CFBP \\
\hline coriandricola & $\begin{array}{l}\text { CFBP } 5010^{\text {PT }} \\
\text { BS } 456 \\
\text { BS } 462\end{array}$ & $\begin{array}{l}\text { Coriandrum sativum } \\
\text { Curled-leaf parsley } \\
\text { Flat-leaf parsley }\end{array}$ & $\begin{array}{l}\text { Germany/1990 } \\
\text { USA/2003 } \\
\text { USA/2002 }\end{array}$ & $\begin{array}{l}- \\
- \\
-\end{array}$ & $\begin{array}{l}\text { CFBP } \\
\text { Carolee } \\
\text { T. Bull } \\
\text { (USA) }\end{array}$ \\
\hline
\end{tabular}


Table 2 (continued)

\begin{tabular}{|c|c|c|c|c|c|}
\hline coronafaciens & CFBP $2216^{\mathrm{PT}}$ & Avena sativa & $\mathrm{UK} / 1958$ & - & CFBP \\
\hline cunninghamiae & CFBP $4218^{\mathrm{PT}}$ & $\begin{array}{l}\text { Cunninghamia } \\
\text { lanceolata }\end{array}$ & China/1995 & - & CFBP \\
\hline daphniphylli & CFBP $4219^{P T}$ & $\begin{array}{l}\text { Daphniphyllum } \\
\text { teigsmanni }\end{array}$ & Japan/1981 & - & CFBP \\
\hline delphinii & CFBP $2215^{\text {PT }}$ & Delphinium sp. & $\begin{array}{l}\text { New } \\
\text { Zealand/1957 }\end{array}$ & - & CFBP \\
\hline dendropanacis & CFBP $3226^{\mathrm{PT}}$ & Dendropanax trifidus & Japan/1979 & - & CFBP \\
\hline dysoxyli & CFBP $2356^{\mathrm{PT}}$ & Dysoxylum spectabile & $\begin{array}{l}\text { New } \\
\text { Zealand/1949 }\end{array}$ & - & CFBP \\
\hline eriobotryae & CFBP $2343^{\mathrm{PT}}$ & Eriobotrya japonica & USA/1970 & - & CFBP \\
\hline garcae & CFBP $1634^{\mathrm{PT}}$ & Coffea arabica & Brasil/1958 & - & CFBP \\
\hline helianthi & CFBP $2067^{\text {PT }}$ & Helianthus annuus & Mexico/ND & - & CFBP \\
\hline hibisci & CFBP $2895^{\text {PT }}$ & Hibiscus rosa-sinensis & USA/1984 & - & CFBP \\
\hline japonica & $\begin{array}{l}\text { MAFF } 301159 \\
\text { MAFF } 301166\end{array}$ & $\begin{array}{l}\text { Triticum aestivum (L.) } \\
\text { Thell. } \\
\text { Hordeum vulgare L. }\end{array}$ & $\begin{array}{l}\text { Japan/ND } \\
\text { Japan/ND }\end{array}$ & $\begin{array}{l}- \\
-\end{array}$ & $\begin{array}{l}\text { MAFF } \\
\text { MAFF }\end{array}$ \\
\hline lachrymans & $\begin{array}{l}\text { CFBP } 6463^{\mathrm{PT}} \\
\text { B } 01557\end{array}$ & $\begin{array}{l}\text { Cucumis sativus } \\
\text { Cucumis L. }\end{array}$ & $\begin{array}{l}\text { Hungary/1958 } \\
\text { ND }\end{array}$ & - & $\begin{array}{l}\text { CFBP } \\
\text { M. Hevesi } \\
\text { (Hungary) }\end{array}$ \\
\hline lapsa & CFBP $1731^{\mathrm{PT}}$ & Zea sp. & ND/1968 & - & CFBP \\
\hline maculicola & $\begin{array}{l}\text { LMG 5071 } \\
\text { LMG } 2208\end{array}$ & $\begin{array}{l}\text { Brassica oleracea } \\
\text { Brassica oleracea }\end{array}$ & $\begin{array}{l}\text { New } \\
\text { Zealand/1965 } \\
\text { UK/1965 }\end{array}$ & $\begin{array}{l}- \\
-\end{array}$ & $\begin{array}{l}\text { LMG } \\
\text { LMG }\end{array}$ \\
\hline mellea & CFBP $2344^{\mathrm{PT}}$ & Nicotiana tabacum & Japan/1968 & - & CFBP \\
\hline mori & $\begin{array}{l}\text { CFBP } 1642^{\text {PT }} \\
\text { MAFF } 302756 \\
\text { MAFF } 810010\end{array}$ & $\begin{array}{l}\text { Morus alba } \\
\text { Morus bombycis Koidz. }\end{array}$ & $\begin{array}{l}\text { Hungary/1958 } \\
\text { Japan/ND }\end{array}$ & $\begin{array}{l}- \\
- \\
-\end{array}$ & $\begin{array}{l}\text { CFBP } \\
\text { MAFF } \\
\text { MAFF }\end{array}$ \\
\hline morsprunorum & $\begin{array}{l}\text { CFBP 2351 } \\
\text { B } 01835 \\
\text { PD5329 } \\
\text { LMG } 2222 \\
\text { CFBP } 3800\end{array}$ & $\begin{array}{l}\text { Prunus domestica } \\
\text { Prunus sp. } \\
\text { ND } \\
\text { Prunus avium } \\
\text { Prunus cerasus }\end{array}$ & $\begin{array}{l}\text { USA/1931 } \\
\text { Hungary/1995 } \\
\text { ND } \\
\text { ND/1958 } \\
\text { UK/ND }\end{array}$ & $\begin{array}{l}- \text { (Psm1) } \\
+(\text { Psm2) } \\
+(\text { Psm1 }) \\
-(\text { Psm2) } \\
+(\text { Psm1 }) \\
-(\text { Psm2 }) \\
+(\text { Psm1 }) \\
-(\text { Psm2 }) \\
-(\text { Psm1 }) \\
+(\text { Psm2 })\end{array}$ & $\begin{array}{l}\text { CFBP } \\
\text { M. Hevesi } \\
\text { (Hungary) } \\
\text { J.D.Janse } \\
\text { (Netherlan } \\
\text { d) } \\
\text { LMG } \\
\text { CFBP }\end{array}$ \\
\hline myricae & $\begin{array}{l}\text { CFBP } 2897^{\text {PT }} \\
\text { MAFF } 302457 \\
\text { MAFF } 302944\end{array}$ & $\begin{array}{l}\text { Myrica rubra } \\
\text { Myrica rubra } \\
\text { Zucc. } \\
\text { Myrica ret rubra } \\
\text { Zucc. }\end{array}$ & $\begin{array}{l}\text { Japan/1978 } \\
\text { Japan/ND } \\
\text { Japan/ND }\end{array}$ & $\begin{array}{l}- \\
- \\
-\end{array}$ & $\begin{array}{l}\text { CFBP } \\
\text { MAFF } \\
\text { MAFF }\end{array}$ \\
\hline oryzae & CFBP $3228^{\text {PT }}$ & Oryza sativa & Japan/1983 & - & CFBP \\
\hline papulans & CFBP $1754^{\text {PT }}$ & Malus sylvestris & Canada/1973 & - & CFBP \\
\hline passiflorae & CFBP $2346^{\mathrm{PT}}$ & Passiflora edulis & $\begin{array}{l}\text { New } \\
\text { Zealand/1962 }\end{array}$ & - & CFBP \\
\hline persicae & LMG $5184^{\mathrm{PT}}$ & Prunus persica & France/1974 & - & LMG \\
\hline philadelphi & CFBP $2898^{\text {PT }}$ & Philadelphus coronarius & $\mathrm{UK} / 1985$ & - & CFBP \\
\hline photiniae & CFBP $2899^{\text {PT }}$ & Photinia glabra & Japan/1976 & - & CFBP \\
\hline pisi & CFBP $2105^{\mathrm{PT}}$ & Pisum sativum & $\begin{array}{l}\text { New } \\
\text { Zealand/1969 }\end{array}$ & - & $\begin{array}{l}\text { CFBP } \\
\text { M. Hevesi }\end{array}$ \\
\hline
\end{tabular}


Table 2 (continued)

\begin{tabular}{|c|c|c|c|c|c|}
\hline & В 01685 & Pisum L. & USA/1957 & - & (Hungary) \\
\hline porri & CFBP $1908^{\mathrm{PT}}$ & Allium porrum & France/1978 & - & CFBP \\
\hline primulae & CFBP $1660^{\mathrm{PT}}$ & Primula sp. & USA/ND & - & CFBP \\
\hline rhaphiolepidis & CFBP $4220^{\mathrm{PT}}$ & Rhaphiolepis umbellata & Japan/1980 & - & CFBP \\
\hline ribicola & CFBP $2348^{\mathrm{PT}}$ & Ribes aureum & $\mathrm{ND} / 1946$ & - & CFBP \\
\hline sesami & CFBP $1671^{\mathrm{PT}}$ & $N D$ & Yugoslavia/1961 & - & CFBP \\
\hline spinaceae & CFBP $5524^{\mathrm{PT}}$ & $N D$ & Japan/ND & - & CFBP \\
\hline striafaciens & CFBP $1674^{\mathrm{PT}}$ & Avena sativa & ND & - & CFBP \\
\hline syringae & $\begin{array}{l}\text { LMG } 1247^{\text {PT }} \\
\text { B } 01461 \\
\text { B } 01558 \\
\text { B } 1893\end{array}$ & $\begin{array}{l}\text { Syringa vulgaris } \\
\text { ND } \\
\text { Prunus sp. } \\
\text { Prunus armeniaca L. }\end{array}$ & $\begin{array}{l}\mathrm{UK} / 1950 \\
\mathrm{ND} \\
\text { Hungary/1978 } \\
\text { Hungary/1999 }\end{array}$ & $\begin{array}{l}- \\
- \\
- \\
-\end{array}$ & $\begin{array}{l}\text { LMG } \\
\text { M. } \\
\text { Hevesi } \\
\text { (Hungary) }\end{array}$ \\
\hline tabaci & $\begin{array}{l}\text { CFBP } 2106^{\text {PT }} \\
\text { B } 01606\end{array}$ & $\begin{array}{l}\text { Nicotiana tabacum } \\
\text { Nicotiana tabacum }\end{array}$ & $\begin{array}{l}\text { Hungary/1959 } \\
\text { Hungary/1995 }\end{array}$ & - & $\begin{array}{l}\text { CFBP } \\
\text { M.Hevesi } \\
\text { (Hungary) }\end{array}$ \\
\hline tagetis & CFBP $1694^{\mathrm{PT}}$ & Tagetes erecta & Zimbabwe/1972 & - & CFBP \\
\hline theae & $\begin{array}{l}\text { CFBP } 2353^{\text {PT }} \\
\text { MAFF } 302853\end{array}$ & $\begin{array}{l}\text { Thea sinensis } \\
N D\end{array}$ & $\begin{array}{l}\text { Japan/1970 } \\
\text { Japan/1975 }\end{array}$ & $\begin{array}{l}- \\
-\end{array}$ & $\begin{array}{l}\text { CFBP } \\
\text { MAFF }\end{array}$ \\
\hline tomato & $\begin{array}{l}\text { CFBP } 2212^{\text {PT }} \\
\text { KFB } 145\end{array}$ & $\begin{array}{l}\text { Lycopersicon esculentum } \\
N D\end{array}$ & $\begin{array}{l}\text { UK/1960 } \\
\text { ND }\end{array}$ & - & $\begin{array}{l}\text { CFBP } \\
\text { A. Prokić, } \\
\text { A } \\
\text { Obradovic } \\
\text { (Serbia) }\end{array}$ \\
\hline ulmi & CFBP $1407^{\mathrm{PT}}$ & Ulmus sp. & Yugoslavia/1958 & - & CFBP \\
\hline viburni & CFBP $1702^{\mathrm{PT}}$ & Viburnum sp. & USA/ND & - & CFBP \\
\hline zizaniae & CFBP $4117^{\mathrm{PT}}$ & Zizania aquatica & USA/1983 & - & CFBP \\
\hline $\begin{array}{l}\text { Pseudomonas } \\
\text { savastanoi pv. } \\
\text { savastanoi. }\end{array}$ & CFBP $1670^{\mathrm{T}}$ & Olea europaea & Yugoslavia/ND & - & CFBP \\
\hline $\begin{array}{l}\text { Pseudomonas } \\
\text { cannabina pv. } \\
\text { alisalensis }\end{array}$ & $\begin{array}{l}\text { CFBP } 6866^{\mathrm{T}} \\
\text { CFBP } 6869\end{array}$ & $\begin{array}{l}\text { Brassica rapa subsp. } \\
\text { Rapa } \\
\text { Eruca vesicaria } \\
\text { sativa }\end{array}$ & $\begin{array}{l}\text { USA/1995 } \\
\text { USA/1995 }\end{array}$ & - & $\begin{array}{l}\text { CFBP } \\
\text { CFBP } \\
\text { Bull et al. } \\
2010\end{array}$ \\
\hline $\begin{array}{l}\text { Pseudomonas } \\
\text { corrugata }\end{array}$ & B 01638 & Lycopersicon esculentum & Hungary/1996 & - & $\begin{array}{l}\text { M. Hevesi } \\
\text { (Hungary) }\end{array}$ \\
\hline
\end{tabular}

*ND no data, $P T$ pathotype strain, $T$ type strain; ** - negative result of amplification with tested primer pairs; + positive result of amplification with tested primer pairs; ${ }^{* *} C F B P$ Collection Francaise des Bacteries Phytopathogenes, Institut National de la Recherche Agronomique, Beaucouzé Cedex, France; $M A F F$ Ministry of Agriculture, Forestry and Fisheries, Tsukuba, Ibaraki, Japan, $L M G$ Laboratorium voor Microbiologie, Universiteit Gent, Gent, Belgium

experimentally determined amplification conditions were used: initial denaturation at $94{ }^{\circ} \mathrm{C}$ for $4 \mathrm{~min} ; 30$ cycles at $94{ }^{\circ} \mathrm{C}$ for $45 \mathrm{~s}, 55-62{ }^{\circ} \mathrm{C}$ for $45 \mathrm{~s}$ for primers Psm1-6F and Psm1-6R (for detection of $P s m 1$ strains) and $50-58{ }^{\circ} \mathrm{C}$ for $45 \mathrm{~s}$ for primers Psm2-8F and Psm2-8R (for detection of Psm2 strains) and $72{ }^{\circ} \mathrm{C}$ for $1 \mathrm{~min}$; and final extension at $72{ }^{\circ} \mathrm{C}$ for
$10 \mathrm{~min}$. The resulting PCR products were separated by electrophoresis on $1.5 \%$ agarose gels as described above.

Real-time PCR with SYBR Green I was conducted in the Bio-Rad CFX96 with SsoAdvanced SYBR Green Supermix (Bio-Rad, Hercules, USA). The reaction mixture in $20 \mu \mathrm{l}$ of total volume contained $1 \times$ reaction SYBR 
Green Supermix and $0.5 \mathrm{mM}$ of each of the following primers: Psm1-1F-RT/Psm1-1R-RT for Psm1 and Psm21F-RT/Psm2-1R-RT for Psm2. Bacterial DNA was used as a template (10 ng per PCR reaction). No-template reactions were used as negative controls. The PCR programme was started from one cycle of denaturation at $98{ }^{\circ} \mathrm{C}$ for $130 \mathrm{~s}$, followed by 35 cycles at $95{ }^{\circ} \mathrm{C}$ for $10 \mathrm{~s}$ and then $60{ }^{\circ} \mathrm{C}$ for $15 \mathrm{~s}$, finished by a melting curve analysis for verification of the specificity of amplification in real-time PCR products. Progressive denaturation of products was carried out at a rising temperature, starting from $65{ }^{\circ} \mathrm{C}$ and continuing to $95{ }^{\circ} \mathrm{C}$, with $0.5{ }^{\circ} \mathrm{C}$ of increment for $5 \mathrm{~s}$ each.

\section{Specificity of designed primers and their usefulness in detection in plant material}

In the first stage of this part of the study, the specificity of the two designed primer pairs was determined with PCR using DNA from all strains of Psm1, Psm2 and Pss as well as strains of atypical taxa (Table 1). In the second stage, the primers were tested with DNA from other $P$. syringae pathovars and related species (Table 2).

In order to assess the suitability of the designed primers for the detection of Psm 1 and Psm 2 strains in plant material, several leaves, shoots and fruits of sweet cherry, sour cherry and plum were collected. Amounts of $100 \mathrm{mg}$ of crushed/cut plant tissue of each organ were placed in $1.9 \mathrm{ml}$ of PBS buffer. For each type of tissue (organ) and host plant, two tubes were prepared (18 tubes in total). One hundred microlitres of bacterial suspension $\left(10^{5} \mathrm{cfu} / \mathrm{ml}\right)$ of the $P s m 1$ reference strain (LMG 2222) or the Psm 2 reference strain (CFBP 3800) were added to nine of the samples (one of each organ and of each plant). One hundred microlitres of sterile water were added to the remaining nine samples, which were tested to verify the purity of the plant material. After $1 \mathrm{~h}$ of shaking incubation at $26^{\circ} \mathrm{C}, 1 \mathrm{ml}$ of washing liquid separate from each of all 18 samples was centrifuged; the resulting pellet was suspended in $100 \mu \mathrm{l}$ of TE buffer, and the DNA was isolated using a Genomic Mini DNA Extraction Kit (A\&A Biotechnology, Gdynia, Poland) according to the manufacturer's instructions.

\section{PCR limit of detection}

The limit of detection of PCR using the SCAR primers was evaluated using DNA extracted from pure bacterial cultures, DNA extracted from plant material that was mixed with suspensions of bacteria and bacterial genomic DNA (gDNA). A PCR assay was carried out with decimal dilutions of bacterial suspensions of strain LMG 2222 or CFBP 3800 (from $\sim 10^{8}$ to $10^{0} \mathrm{cfu} / \mathrm{ml}$ ). DNA was isolated from $1 \mathrm{~mL}$ of each dilution using a Genomic Mini DNA Extraction Kit (A\&A Biotechnology) according to the protocol supplied by the manufacturer. To determine the limit of detection of bacteria in the plant material, 100-mg portions of stems and leaves of sweet cherry (for Psm 1 primers) or sour cherry (for $P s m 2$ primers) and $100 \mu$ of the previously prepared 10 -fold serial dilutions of bacterial suspensions (from $\sim 10^{8}$ to $10^{0} \mathrm{cfu} / \mathrm{ml}$ ) or $100 \mu \mathrm{l}$ of sterile water, used as a control of material purity, were added to $1.9 \mathrm{~mL}$ of PBS buffer and shaken for $30 \mathrm{~min}$ at $26^{\circ} \mathrm{C}$. After incubation, the washings were centrifuged (8,000 rpm, $5 \mathrm{~min})$; the resulting pellet was suspended in $100 \mu$ of TE buffer, and DNA was isolated using the Genomic Mini DNA Extraction Kit (A\&A Biotechnology) according to the manufacturer's instructions. The sensitivity of gDNA detection was checked using 2-fold serial dilutions of gDNA isolated (11 ng to $\sim 11 \mathrm{fg}$ per PCR reaction for Psm 1 and $14 \mathrm{ng}$ to $\sim 14 \mathrm{fg}$ per PCR reaction for Psm2) using the method described by Aljanabi and Martinez (1997), with slight modifications described by Kałużna et al. (2012). The PCR efficiency was calculated from the slope of the standard curve generated for each run in the following equation $E=10^{(-1 / \text { slope })}$ where $E=2$ and corresponds to $100 \%$ efficiency (Ramakers et al. 2003).

\section{Results}

\section{Phenotypic characterisation}

All 168 isolates have been classified into species $P$. syringae LOPAT group Ia. GATTa and L-lactate utilisation tests allowed further discrimination of pathovars and races: 49 isolates were identified as P. syringae pv. morsprunorum race 1 (Psm 1$), 10$ as race 2 of this pathovar, 53 as pathovar syringae (Pss) and 56 as belonging to atypical taxa, having most of the features of PSS without, however, the ability of esculine hydrolysis (lack of $\beta$-glucosidase activity) (Table 1).

\section{PCR MP}

To select specific fragments of the taxon, the PCR MP method was applied using DNA from different strains of $P$. syringae (Figs. 1 and 2; Table 1). The obtained PCR MP patterns corresponded to phenotypically determined pathovars and races. Similar electrophoretic patterns were obtained for races within pathovar morsprunorum, confirming their homogeneity; however, different patterns were observed for strains belonging to pathovar syringae. For Psm 1 and Psm2, the products that were specific and were shared between all strains of each taxa were selected, cloned and sequenced. Two products specific for Psm 1 (after digestion by Pst I) had sizes of 1,208 and $1,128 \mathrm{bp}$, while the unique amplification product (after digestion by TaqI) for strains of Psm2 was 781 bp long. No specific and unique band was found for strains of PSS. 
Fig. 1 Electrophoretic patterns obtained after polymerase chain reaction melting profile (PCR MP) of fluorescent

Pseudomonads with primer Pst1: Lane 1- $M$-marker 100-bp ladder (Genoplast, Rokocin,

Poland); pathovar morsprunorum race 1 isolates: 2-LMG 2222, 3-702, 4-710, 5-755, 6787, 7-782, 8-793, 9-701A; pv. morsprunorum race 2 isolates: 10 - CFBP 3800, 11-719, 12$733,13-732,14-745,15-$ 764, 16-701; pv. syringae isolates: 17-LMG 1247, 18 $2905,19-760 ; 20-762,21-$ 702A, 22-757, 23-753, 24763, 25-M-marker 100-bp PCR Molecular Ruler (Bio-Rad, Hercules, USA)

Fig. 2 Electrophoretic patterns obtained after polymerase chain reaction melting profile (PCR MP) of fluorescent

Pseudomonads with primer Taq1: Lane 1-M-marker 100-bp ladder (Genoplast, Rokocin, Poland); pathovar morsprunorum race 1 isolates: $2-$ LMG 2222 , 3-25b, 4-28a, 5-107, 6201, 7-701A, 8-755, 9-771; pv. morsprunorum race 2 isolates: 10-CFBP 3800, 11-77, 12$701,13-732,14-733,15-$ 745,16 - 764; pv. syringae isolates: 17-LMG 1247, 18 $2905,19-68 ; 20-110,21-$ $141,22-286,23-415,24-$ 763, 25-M-marker 100-bp PCR Molecular Ruler (Bio-Rad, Hercules, USA)

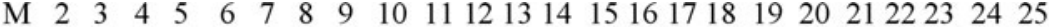

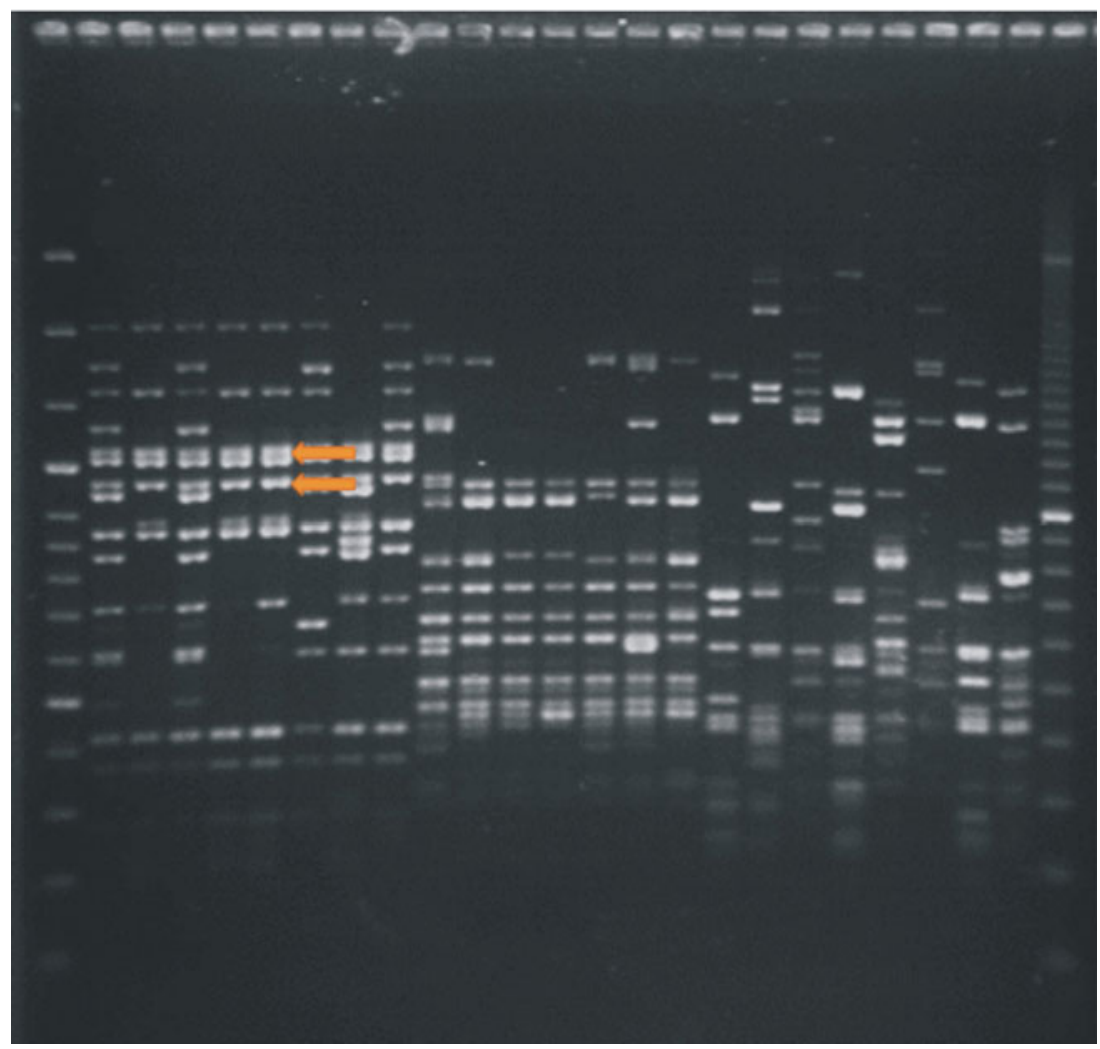

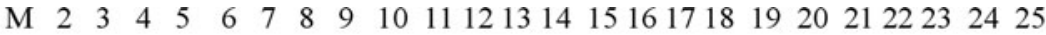

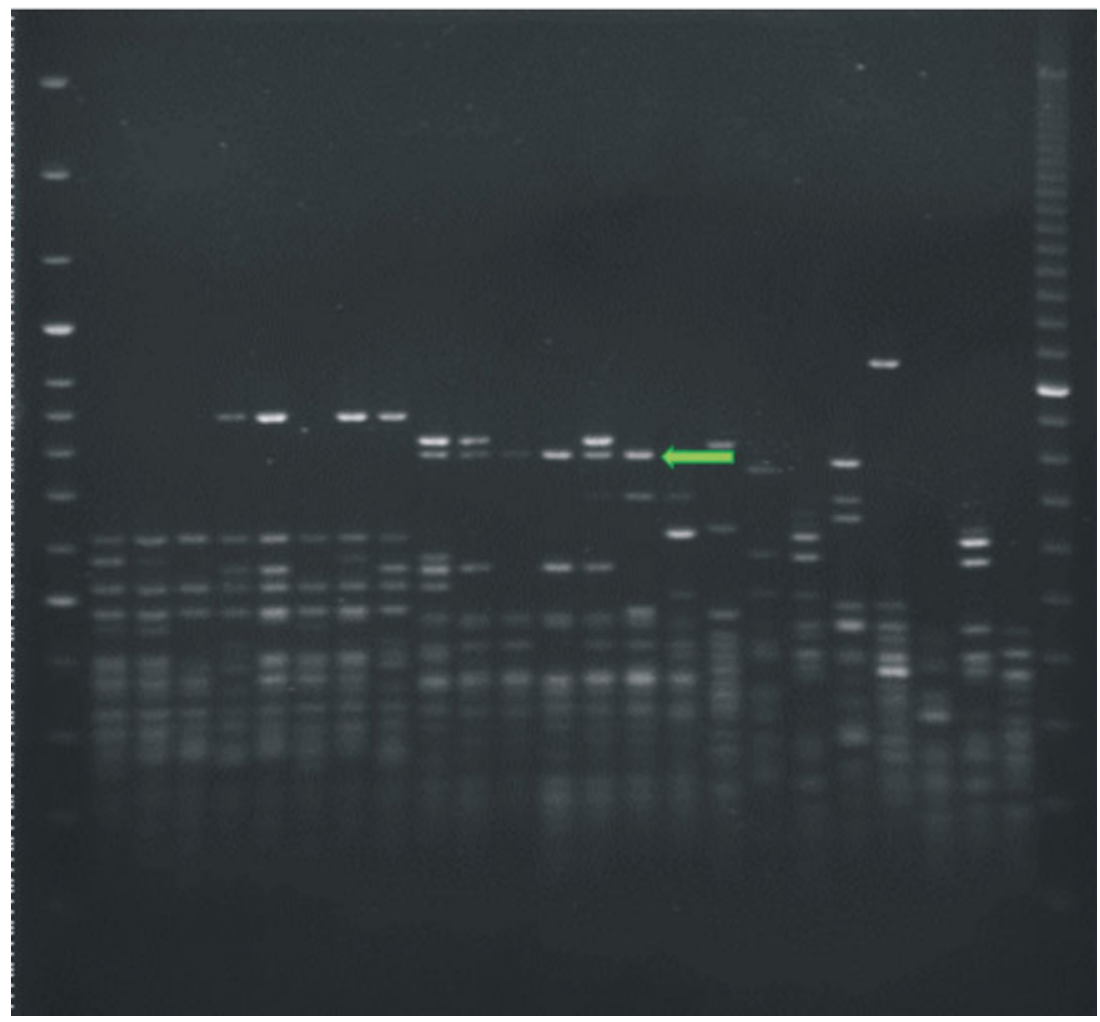




\section{Design of SCAR primers}

The nucleotide sequences obtained for the Psm 1 and Psm2 fragments were used to design different SCAR primers. After validation, the most specific primers for conventional and real-time PCR were selected (Table 3). A BLAST analysis of selected primer sequences showed no similarity to any bacterial sequences in GenBank.

\section{Dot blot hybridisation}

The dot blot results confirmed the high specificity of the selected markers towards the target pathogens. Using probe Psm1, positive hybridisation results (dark dots) were observed with all tested Psm1 strains, and no unspecific hybridisation was observed with DNA from any non- $P s m 1$ pseudomonads. Similarly, probe $P_{s m} 2$ was exclusively specific for the tested Psm 2 strains. Additionally, the hybridisation results showed that the selected DNA regions were present in all their respective target strains, confirming their stability (Fig. 3).

\section{Specificity of designed primers and usefulness in detection in plant material}

The PCR assays using DNA from all tested $P$. syringae strains including reference strains (Table 1), as well as DNA from strains of other species within the Pseudomonas genus (Table 2), showed that all the designed primers were specific for their respective taxa. PCR assays using primers Psm1-6F/ 6R and Psm1-1F-RT/1R-RT, specific for Psm1, successfully amplified the expected PCR products 793 bp (Fig. 4) and 101 bp (Fig. 5), respectively, using DNA from all strains of Psm1. No amplification was observed when DNA from strains identified as Psm 2 or Pss and strains of atypical taxa were used. Amplification using primers Psm2-8F/8R and Psm2-1F-RT/1R-RT, designed for detection of Psm2, was achieved with DNA from all strains of Psm2, resulting in PCR products of expected lengths of 410 bp (Fig. 6) and $104 \mathrm{bp}$, respectively. No increase in fluorescence was observed with DNA from Psm 1 or Pss and strains of atypical taxa. The melting curves of the reaction products obtained from real-time PCR revealed a single peak with a melting temperature of $80^{\circ} \mathrm{C}$ or $77^{\circ} \mathrm{C}$ for Psm 1 and Psm2, respectively. Also, neither unexpected nor additional peaks in the product melting curves were observed, which clearly excluded possibilities or tendency of the primers to form dimers. Moreover, none of the four tested primer pairs amplified the DNA of 79 strains of other pathovars of $P$. syringae and other species (Table 2).

The usefulness of the designed primers for detection of Psm 1 and Psm 2 strains in plant material was assessed with PCR assays using DNA extracted from a mixture of plant tissues and a suspension of target bacteria. The results confirmed the specificity of selected primer-pairs since positive amplification was achieved in mingled samples, while no nonspecific amplification was observed in samples without bacteria addition. Additionally, these assays showed that the proposed PCR detection methodology was not affected by potential inhibitors present in plant samples.

\section{Limit of detection of $P$. syringae pv. morsprunorum for conventional and real-time PCR}

Both tested primer pairs designed for conventional PCR allowed for the detection of $10^{\circ} \mathrm{cfu} /$ reaction of Psm 1 and $10^{1}$ Psm 2 in pure culture. Regarding the presence of bacteria in different organs of sweet and sour cherries, it was possible to detect $10^{\circ}$ and $10^{1} \mathrm{cfu} / \mathrm{reac}-$ tion for sweet cherry leaves and shoots, respectively, using the $P s m 1$-specific primers and $10^{2}$ cfu/reaction for sour cherry leaves and shoots using the Psm2-

Table 3 Primers specific for strains of Psm 1 and Psm2

\begin{tabular}{|c|c|c|c|c|}
\hline & $\begin{array}{l}\text { Primer } \\
\text { name }\end{array}$ & $\begin{array}{l}\text { Primer } \\
\text { sequence }\end{array}$ & $\mathrm{T}_{\mathrm{m}}$ & $\begin{array}{l}\text { Product } \\
\text { length }\end{array}$ \\
\hline \multirow[t]{4}{*}{ Conventional PCR } & Psm1-6F & 5'-TGTTCCCGGCCATCCAATA-3' & $51.1{ }^{\circ} \mathrm{C}$ & \multirow[t]{2}{*}{$793 \mathrm{bp}$} \\
\hline & Psm1-6R & $\begin{array}{l}\text { 5'-ATCCGCATCAGTCAAAATAGTCAT- } \\
3^{\prime}\end{array}$ & $52.3^{\circ} \mathrm{C}$ & \\
\hline & Psm2-8F & $\begin{array}{l}\text { 5'-CTTTTTAGATGGTGAGGTTTTGTA- } \\
3^{\prime}\end{array}$ & $50.6^{\circ} \mathrm{C}$ & \multirow[t]{2}{*}{$410 \mathrm{bp}$} \\
\hline & Psm2-8R & 5'-ACTTTCGGATCATCGTTTTCTA-3' & $49.2^{\circ} \mathrm{C}$ & \\
\hline \multirow[t]{4}{*}{ Real-time PCR } & Psm1-1F-RT & 5'-TCCCGGCCATCCAATACTTTACG-3' & $57.1^{\circ} \mathrm{C}$ & \multirow[t]{2}{*}{$101 \mathrm{bp}$} \\
\hline & $\begin{array}{l}\text { Psm1-1R- } \\
\quad \text { RT }\end{array}$ & 5'-ACGCTTCATGGTGTCTTGTTTA-3' & $51.1{ }^{\circ} \mathrm{C}$ & \\
\hline & Psm2-1F-RT & 5'-GGTTTGCCTTTTCCTCAG-3' & $48^{\circ} \mathrm{C}$ & \multirow[t]{2}{*}{$104 \mathrm{bp}$} \\
\hline & $\begin{array}{l}\text { Psm2-1R- } \\
\text { RT }\end{array}$ & 5'-ATTGCATTACTTCTTTGTTGC-3' & $46.5^{\circ} \mathrm{C}$ & \\
\hline
\end{tabular}

$F$ forward primer, $R$ reverse primer, $R T$ real-time, $T m$ melting temperature 


\begin{tabular}{|c|c|c|c|c|c|c|c|c|c|c|c|c|}
\hline & 1 & 2 & 3 & 4 & 5 & 6 & 7 & 8 & 9 & 10 & 11 & 12 \\
\hline A & $25 a$ & 28a & $29 a$ & 58 & 59 & 61 & 66 & 68 & 69 & 71 & 72 & 83 \\
\hline B & 86 & 87 & 88 & 89 & 90 & 91 & 93 & 94 & 95 & 96 & 98 & 100 \\
\hline C & 103 & 106 & 107 & 109 & 110 & 112 & 115 & 117 & 118 & 119 & 120 & 122 \\
\hline D & 141 & 147 & 158 & 165 & 174 & 177 & 184 & 192 & 199 & 201 & 202 & 203 \\
\hline E & 204 & 205 & 206 & 209 & 210 & 211 & 213 & 214 & 215 & 216 & 217 & 218 \\
\hline $\mathbf{F}$ & 219 & 220 & 221 & 222 & 226 & 227 & 229 & 233 & 234 & 235 & 236 & 237 \\
\hline G & 239 & 240 & 242 & 244 & 245 & 247 & 248 & 250 & 256 & 257 & 258 & 259 \\
\hline H & 264 & 266 & 271 & 274 & 276 & 280 & 283 & 291 & 373 & 374 & 376 & 415 \\
\hline I & 417 & $420 a$ & 435 & 437 & 439 & 441 & 442 & 460 & 663 & 671 & 701 & $701 \mathrm{~A}$ \\
\hline J & 702 & $702 \mathrm{~A}$ & 710 & 719 & 732 & 733 & 745 & 753 & 755 & 757 & 760 & 762 \\
\hline K & 763 & 764 & 771 & 782 & 787 & 788 & 791 & 793 & 909 & 910 & 914 & 949 \\
\hline L & 959 & 963 & 966 & 967 & 968 & $969 a$ & $970 a$ & $970 \mathrm{~b}$ & $971 a$ & $971 b$ & 972 & 973 \\
\hline M & 982 & 1017 & 1021 & 1061 & 1247 & 2222 & 2905 & 3800 & CFBP1407 & CFBP1617 & CFBP1694 & CFBP1731 \\
\hline $\mathbf{N}$ & CFBP1754 & CFBP2067 & CFBP2105 & CFBP2213 & CFBP2215 & CFBP2339 & CFBP2346 & CFBP3226 & CFBP5010-2 & LMG2208 & MAFF301159 & C- \\
\hline
\end{tabular}

\section{Psm 1 probe}

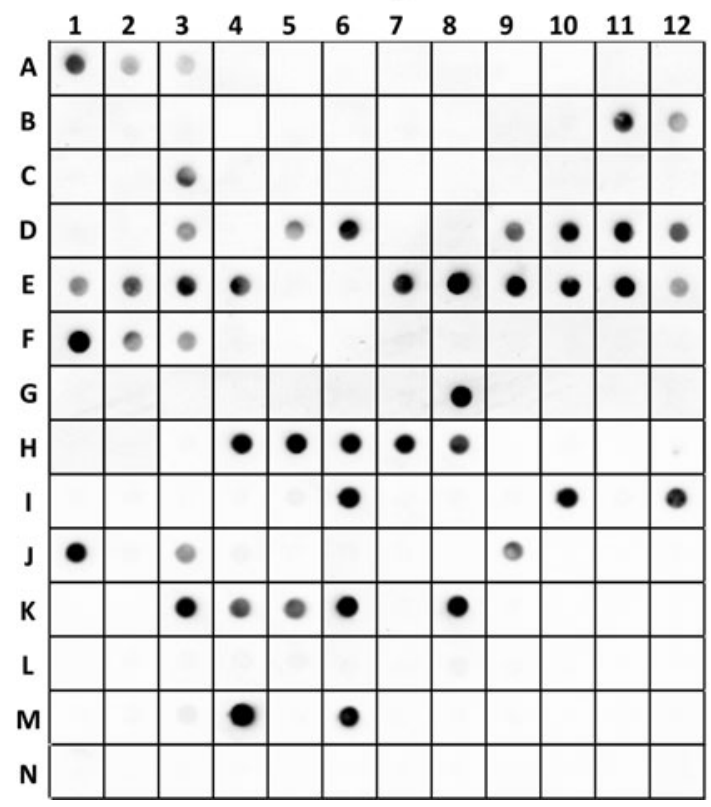

Fig. 3 Dot blot validation of probes Psm1 and Psm2. The probes were evaluated with total DNA from 167 strains; including P. syringae strains isolated from stone fruit trees, reference strains and others pathovars of P. syringae from the CFBP culture collection. The table grid above

specific primers. The sensitivity (LOD, limit of detection) of the detection in the conventional PCR assay was $\sim 4 \mathrm{pg}$ for Psm 1 strain 199 and $\sim 5 \mathrm{pg}$ for Psm2 strain 745 when aliquots of serial 2-fold dilutions of purified DNA were used which corresponds to the order of magnitude $\sim 10^{1}-10^{2}$ cfu/reaction.

Both tested primer pairs designed for Psm 1 and Psm2 strains using real-time PCR allowed the detection of $10^{\circ} \mathrm{cfu} /$ reaction of $P s m 1$ or $P s m 2$ in pure culture and in plant material. Only the expected products and a single peak with melting temperature were obtained. Standard curves using template DNA from bacterial suspensions, DNA from plant material with additions of bacterial suspensions and bacterial gDNA showed high

\section{Psm 2 probe}

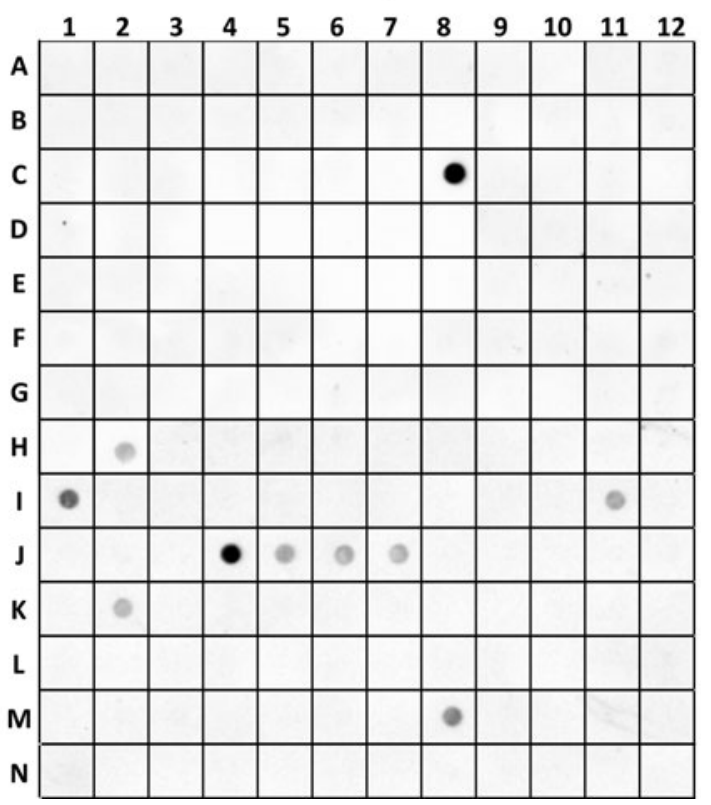

represents the coordinates of each strain tested in the dot blot, which are identified by their abbreviations further detailed in Tables 1 and 2 . Positive hybridization signals are visualised as dark dots

amplification efficiency and linearity of the data (Table 4). An exception occurred for the products obtained from shoots of sweet cherry with additions of bacterial suspensions of Psm1. Although linearity was quite good, the noted efficiency of $83 \%$ was not in the range considered acceptable (90-110\%). Moreover, the efficiency obtained for the mixture of shoots of sour cherry and Psm 2 suspension when testing with primers for Psm2 was also lower compared to DNA template from sour cherry leaves and bacterial suspension alone. The sensitivity (LOD) of the detection in the real-time PCR assay when using gDNA ranged from $\sim 30$ to 100 fg for Psm 1 strain 199 and $\sim 10$ to $50 \mathrm{fg}$ for Psm2 strain 745 when $1.0-\mu 1$ aliquots of serial 2-fold dilutions of 


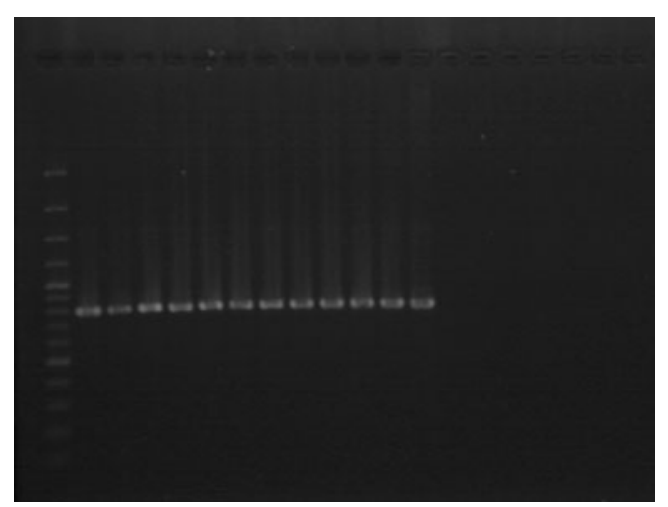

Fig. 4 Evaluation of primers Psm1-6F and Psm1-6R for identification of P. syringae pv. morsprunorum race 1: M-O'GeneRuler 100-3000 bp (Thermo Scientific, Vilnius, Lithuania), strains Psm1: strains Psm1: 2LMG 2222, 3-28a, 4-29a, 5-38a, 6-175, 7-199, 8-201, 9-203, 10-205, 11-274, 12-755, strains Psm2:13 - CFBP 3800, 14-732, strains Pss: 15-LMG 1247, 16 - 760, strains of atypical taxon: 17-58, $18-970 \mathrm{a}, 19-\mathrm{K}-$

purified DNA were used which corresponds to the order of magnitude $\sim 10^{\circ} \mathrm{cfu} /$ reaction (Table 4 ).

\section{Discussion}

In this study, the methods and tools enabling the rapid and highly specific identification and detection of bacterial canker causal agent $P$. syringae pv. morsprunorum races 1 and 2 were developed. The methods based on the use of specific primers

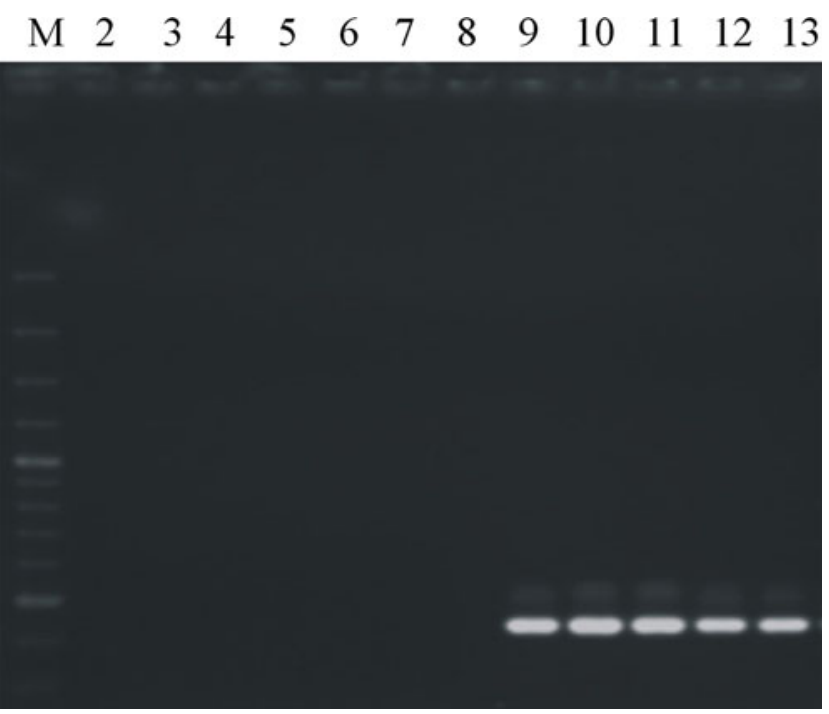

Fig. 6 Evaluation of primers Psm2-8F and Psm2-8R for identification of P. syringae pv. morsprunorum race 2: M-O'GeneRuler 100-3000 bp (Thermo Scientific, Vilnius, Lithuania), strains Psm 1: 2-25b, 3-250, 4-788; strains Pss: 5-68, 6-110; strains of atypical taxon: 7-61, 8970a; strains Psm2: 9—77, 10—CFBP3800, 11-77, 12-745, 13-764

designed for conventional and real-time PCR allow in routine testing for omitting the application of often time-consuming methods of classical microbiology, fingerprinting methods or housekeeping gene sequence analysis used until now by other authors (Vicente and Roberts 2007; Gilbert et al. 2009). Of course in critical cases (i.e. first reports, claims, etc.) these other methods are still indispensable. Our newly developed

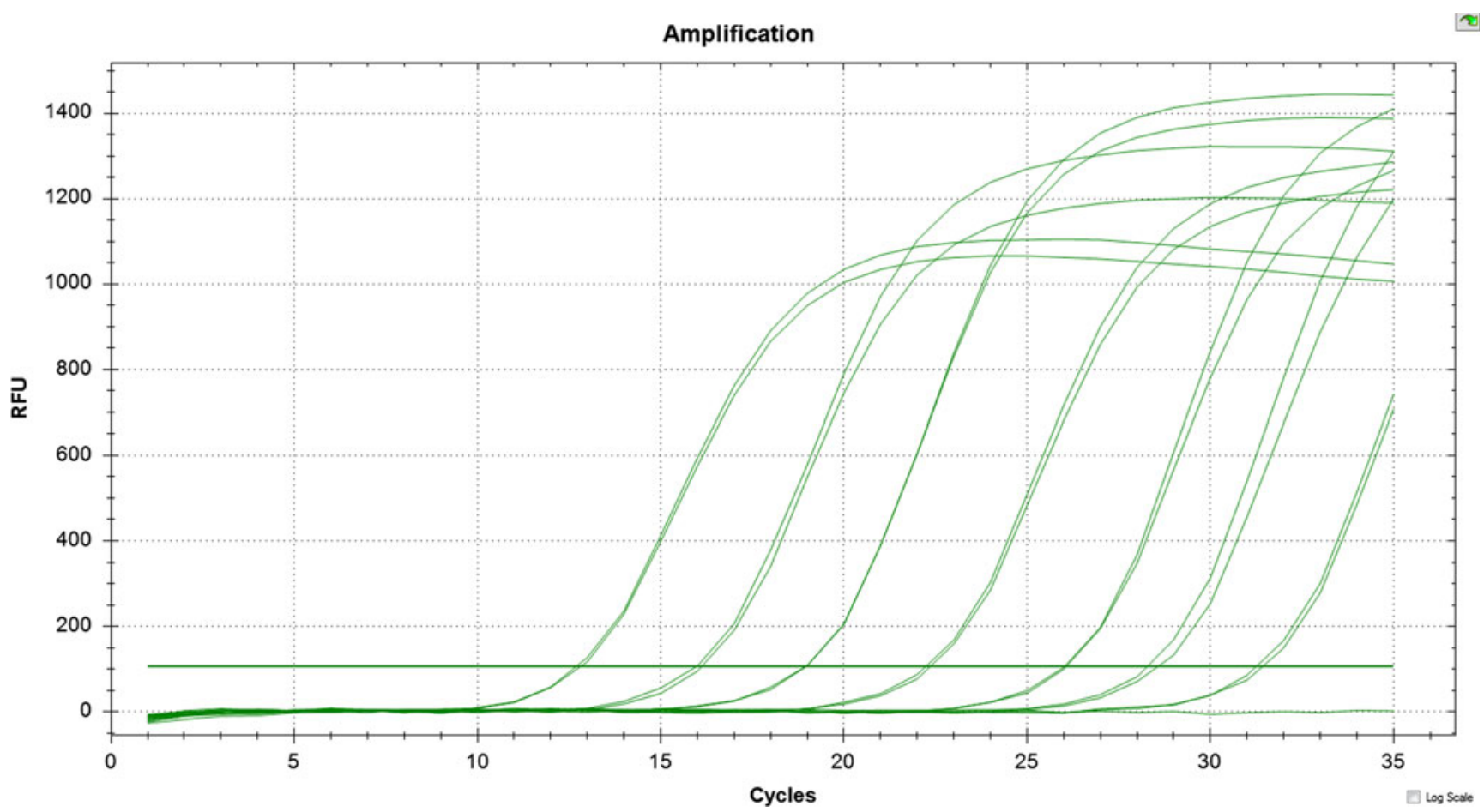

Fig 5 Real-time PCR with SYBR Green I (Bio-Rad, Hercules, USA) for specific detection of DNA from suspension of Psm 1 strain LMG2222 (example). Fluorescence signal is related to the amount of template. Samples from $10^{6}, 10^{5}, 10^{4}, 10^{3}, 10^{2}, 10^{1}$ and $10^{0}$ cfu/reaction 
Table 4 Important parameters of real-time polymerase chain reaction (PCR) runs evaluated through the analysis of standard curves generated with different DNA templates of $P$. syringae pv. morsprunorum races 1 and 2

\begin{tabular}{|c|c|c|c|c|}
\hline Template & $\mathrm{E}(\%)^{\mathrm{a}}$ & $\mathrm{R} 2^{\mathrm{b}}$ & Slope $^{\mathrm{c}}$ & $Y=$ int $^{\mathrm{d}}$ \\
\hline Psm1 (DNA from bacterial suspension) & 103 & 0.998 & -3.252 & 35.445 \\
\hline Psm $1+$ sweet cherry leaves & 99.7 & 0.965 & -3.328 & 36.551 \\
\hline Psm $1+$ sweet cherry shoots & 83.0 & 0.989 & -3.810 & 43.932 \\
\hline Psm 1 gDNA & 99.2 & 0.997 & -3.342 & 18.425 \\
\hline Psm2 (DNA from bacterial suspension) & 99.8 & 0.995 & -3.326 & 33.093 \\
\hline Psm $2+$ sour cherry leaves & 99.3 & 0.999 & -3.338 & 32.451 \\
\hline Psm $2+$ sour cherry shoots & 91.4 & 0.994 & -3.548 & 35.130 \\
\hline Psm 2 g DNA & 99.2 & 0.991 & -3.342 & 17.805 \\
\hline
\end{tabular}

${ }^{\mathrm{a}} E=\mathrm{PCR}$ efficiency; ideally the efficiency should be $100 \%$, meaning that for each cycle the amount of product doubles; high/acceptable amplification efficiency $(90-110 \%)$. Efficiency $=10^{(-1 / \text { slope })}-1$

${ }^{\mathrm{b}} \mathrm{R} 2$ is a measure of data linearity amongst technical replicates of serial dilutions; indicates how good one value is in predicting another; $\mathrm{R} 2=1$ is perfect

${ }^{\mathrm{c}}$ The slope of the log-linear phase of the amplification reaction is a measure of reaction efficiency. To obtain accurate and reproducible results, reactions should have an efficiency as close to $100 \%$ as possible, equivalent to a slope of -3.32

${ }^{\mathrm{d}} Y=$ int represents the value of $\mathrm{Ct}$ where the curve crosses the y-axis

methods and tools are very useful and invaluable in both epidemiological studies and in development of protection programmes for stone fruits against bacterial canker.

Using the genetic fingerprinting PCR MP method, we demonstrated the diversity of $P$. syringae strains, which was very important in the selection of specific DNA fragments for two races of P. syringae pv. morsprunorum. Based on the obtained nucleotide sequences of these fragments, Psm1- and Psm2specific SCAR primers were designed. The specificity of the designed primers for Psm and amplified regions was confirmed by BLAST, since the fragments did not show (at present) any significant similarity hits within the NCBI database. Due to the high electrophoretic profile heterogeneity obtained for Pss strains arising from their high genetic diversity confirmed already by other authors (Vicente and Roberts 2007; Gilbert et al. 2009; Kałużna et al. 2010a, b), it was not possible to find a common DNA fragment for all strains belonging to this taxon.

Commonly used methods for designing SCAR primers include rep-PCR (repetitive PCR) (Sangdee et al. 2013), randomly amplified polymorphic DNA (RAPD) (Liu et al. 2012; Cheng et al. 2015), amplified fragment length polymorphism (AFLP) (Zhang et al. 2012), PCR with universal rice primers (URP-PCR) (Lim et al. 2009) and intersimple sequence repeat (ISSR) (Giaj Merlera et al. 2015). Although the PCR MP method was described so far as helpful in the study of genetic diversity of bacteria and yeast (Leibner-Ciszak et al. 2010; Kałużna et al. 2010b, 2014; Zasada et al. 2014), it has not been previously reported to be used for the selection of SCAR markers. In this work, the PCR MP is for the first time used for the design of SCAR primers specific for detection of plant pathogenic bacteria.
The results obtained in this study showed that the designed SCAR primers can be applied for specific, direct detection of strains belonging to Psm 1 or Psm2, both in pure culture and infected plant material. Their specificity was confirmed by PCR, using DNA from several Pseudomonas spp. strains, which showed that positive amplification occurred only with DNA of the targeted taxa strains. This is especially significant in the case of strains of atypical taxa and pathovars of $P$. syringae (i.e. pv. syringae and pv. avii, which also infect cherry (Ménard et al. 2003; Renick et al. 2008)) to exclude that symptoms are connected to another taxa/pathogen or to abiotic factors. Importantly, when testing the developed primers in conventional PCR, using DNA isolated from a mixture of plant material and bacteria of $P s m 1$ or $P s m 2$, the suppression of amplification by potential plant inhibitors like polyphenols and pesticide residues, as reported by Puławska et al. (1997), was not found. Additionally, for DNA from the asymptomatic plant material without addition of bacterial DNA, no positive amplification was observed. This means that the designed primers did not react with DNA of potential bacteria naturally inhabiting the plant material, which is essential to prevent false-positive diagnostic results. However, in the case of real-time PCR, which is the more sensitive method, some effects of plant material were noted. Although standard curves using different template DNA showed the high amplification efficiency and linearity of the data for the majority of DNA tested, for shoots of sweet cherry with additions of bacterial suspensions the efficiency was below the range considered acceptable, indicating higher dilution of those templates than expected. Also, a decrease of efficiency (Table 4) in the case of sour cherry shoots was observed. The results therefore may indicate the influence of shoots for more sensitive real-time PCR reactions. 
The designing of primers for both systems, conventional and real-time PCR, makes the developed diagnosis system more accessible to a wider group of researchers, as many laboratories do not have access to special equipment or specialised personnel to perform the real-time PCR or have less funds. However, as described, the real-time PCR procedure is much faster (whole reaction with melting curve analysis is about $1 \mathrm{~h}$ from the beginning with SsoAdvanced SYBR Green Supermix); it allows the use of DNA quickly extracted from pure culture by the boiling method, without loss of detection resolution, and also excludes additional timeconsuming post-PCR processes (i.e. agarose gel electrophoresis). Therefore, using this technique, it is possible to obtain a very fast response about the causal agent of the disease. However, it should be noted that this system is highly sensitive and that false-positive results can occur. The risk of falsepositive results due to cross-contamination during preparation of the PCR can be minimised by using negative controls and high discipline during work (e.g., application of tips with filters during the DNA isolation step). Additionally, positive results obtained during those of the final PCR cycles should be treated as suspect only, for which additional, more detailed investigations should be conducted. Moreover, during all the assays the melting curve analysis is recommended to exclude nonspecific amplicons (as a consequence of which are visible in each run as the rest of the analysed specific ones). Dot blot hybridisation confirmed that the two selected DNA regions were highly specific for their target genomospecies and stable amongst all tested isolates of either Psm 1 or Psm2, which is essential for preventing false-positive and false-negative results, respectively as much as possible.

In summary, when compared with so-far available methods for identification and differentiation of causal agents of stone fruit bacterial canker based on phenotypic characters, fingerprinting methods or MLST, the use of pathovar-specific primers allowed for greatly shortening the time required for diagnosis, while highly increasing assay accuracy and lowering detection limit. Moreover, this PCR-based method is relatively simple and inexpensive, and it does not require the timeconsuming step of pre-incubation on microbiological media (Schaad et al. 1995). Even in the presence of potential inhibitors present in plant material, which can affect the limit of detection, we could detect 1 and $3 \times 10^{2}$ cfu/reaction using primers specific for Psm 1 and Psm 2 in conventional PCR. A similar detection sensitivity in conventional PCR was obtained by other authors in their identification systems for other phytopathogens (Catara et al. 2000; Kerkoud et al. 2002; Biondi et al. 2013). The sensitivity of real-time PCR was higher than in the case of conventional ones, as $1 \mathrm{cfu} /$ reaction was detected when different templates were used. This is especially important in the case of naturally infected material in the presence of a small amount of pathogen DNA, which be detected in a very short time. The limit of detection when using gDNA was in the range from $\sim 4-5$ pg in conventional and $\sim 10-100$ fg in real-time PCR for both taxa, which are similar to results obtained for $P$. syringae pv. actinidiae (Gallelli et al. 2014) and Clavibacter michiganensis subsp. sepedonicus (Cho et al. 2015). The high sensitivity of the developed assay (obtained in our hands) will be invaluable for detecting the target bacteria in the early latent period of the disease, allowing growers to undertake appropriate prevention or protection programmes.

Acknowledgments This work was conducted within the framework of COST Action FA1104 and was partially financed by the National Science Centre, Poland, Grant DEC-2013/08/M/NZ9/00138 and by the Polish Ministry of Science and Higher Education Grant No. 118/N-COST/ 2008/0. The purchase of the strains from CFBP collection was financed by Polish Ministry of Science and Higher Education - special purpose grand for young scientists, decisions no: 210727/E-690/M/2013. Pedro Albuquerque was supported by the project 'Genomics Applied to Genetic Resources', co-financed by the North Portugal Regional Operational Programme 2007/2013 (ON.2 - O Novo Norte), under the National Strategic Reference Framework, through the European Regional Development Fund. The authors would like to thank Mrs. Halina Kijańska for excellent technical help. Authors want to thank Robert W. Jackson (University of Reading, UK); Carolee T. Bull (United States Department of Agriculture Agricultural Research Service, USA); Hiroyuki Sawada (National Institute of Agrobiological Sciences, Japan); Maria Hevesi (Corvinus University of Budapest, Hungary); Jaap. D. Janse (Department Laboratory Methods and Diagnostics Dutch General Inspection Service (NAK), The Netherlands); Andjelka Prokić and Aleksa Obradovic (University of Belgrade, Serbia); Olaf Schmidt (University of Hamburg, Germany); and Klaus Geider (Julius Kühn-Institute, Heidelberg, Germany) for kind supplying of some Pseudomonas strains.

\section{Compliance with ethical standards}

Conflict of interest The authors of the paper declare that they have no conflict of interest.

Ethical statement This article does not contain any studies with human participants or animals performed by any of the authors.

Open Access This article is distributed under the terms of the Creative Commons Attribution 4.0 International License (http:// creativecommons.org/licenses/by/4.0/), which permits unrestricted use, distribution, and reproduction in any medium, provided you give appropriate credit to the original author(s) and the source, provide a link to the Creative Commons license, and indicate if changes were made.

\section{References}

Agrios GN (2005) Plant diseases caused by prokaryotes: bacteria and mollicutes, chapter 12. In: Agrios GN (ed) Plant Pathology, 5th edn. Elsevier Academic Press, San Diego, USA, p 616-703

Ajmone-Marsan P, Valentini A, Cassandro M, Vecchiotti-Antaldi G, Bertoni G, Kuijper M (1997) AFLP markers for DNA fingerprinting in cattle. Anim Genet 28:418-426

Albuquerque P, Caridade CMR, Marcal ARS, Cruz J, Cruz L, Santos CL, Mendes MV, Tavares F (2011) Novel markers for identification of Xanthomonas fragariae, Xanthomonas axonopodis pv. phaseoli and Xanthomonas fuscans subsp. fuscans using a dot blot platform 
coupled with automatic data analysis. Appl Environ Microbiol 77: $5619-5628$

Aljanabi SM, Martinez I (1997) Universal and rapid salt extraction of high quality genomic DNA for PCR-based techniques. Nucl Acids Res 25:4692-4693

Altschul SF, Madden TL, Schaffer AA, Zhang J, Zhang Z, Miller W, Lipman DJ (1997) Gapped BLAST and PSI-BLAST: a new generation of protein database search programs. Nucl Acids Res 25:33893402

Bereswill S, Bugert P, Volksch B, Ullrich M, Bender CL, Geider K (1994) Identification and relatedness of coronatine-producing Pseudomonas syringae pathovars by PCR analysis and sequence determination of the amplification products. Appl Environ Microbiol 60:2924-2930

Biondi E, Galeone A, Kuzmanovic N, Ardizzi S, Lucchese C, Bertaccini A (2013) Pseudomonas syringae pv. actinidiae detection in kiwifruit plant tissue and bleeding sap. Ann Appl Biol 162:60-70

Bull CT, Manceau C, Lydon J, Kong H, Vinatzer BA, Fischer-Le Saux M (2010) Pseudomonas cannabina pv. cannabina pv. nov., and Pseudomonas cannabina pv. alisalensis (Cintas Koike and Bull, 2000) comb. nov., are members of the emended species Pseudomonas cannabina (ex Sutic \& Dowson 1959) Gardan, Shafik, Belouin, Brosch, Grimont \& Grimont 1999. Syst Appl Microbiol 33:105-115

Bull CT, Clarke CR, Cai R, Vinatzer BA, Jardini TM, Koike ST (2011) Multilocus sequence typing of Pseudomonas syringae sensu lato confirms previously described genomospecies and permits rapid identification of $P$. syringae pv. coriandricola and $P$. syringae pv. apii causing bacterial leaf spot on parsley. Phytopathology 101:847-858

Bultreys A, Gheysen I (1999) Biological and molecular detection of toxic lipodepsipeptide-producing Pseudomonas syringae strains and PCR identification in plants. Appl Environ Microbiol 65:1904-1909

Bultreys A, Kałużna M (2010) Bacterial cankers caused by Pseudomonas syringae on stone fruit species with special emphasis on the pathovars syringae and morsprunorum race 1 and race 2. J Plant Pathol 92:21-33

Bultreys A, Gheysen I, de Hoffmann E (2006) Yersiniabactin production by Pseudomonas syringae and Escherichia coli and description of a second yersiniabactin locus evolutionary group. Appl Environ Microbiol 72:3814-3825

Catara V, Arnold D, Cirvilleri G, Vivian A (2000) Specific oligonucleotide primers for the rapid identification and detection of the agent of tomato pith necrosis, Pseudomonas corrugata, by PCR amplification: evidence for two distinct genomic groups. Eur J Plant Pathol 106:753-762

Cheng J, Long Y, Khan MA, Wei C, Fu S, Fu J (2015) Development and significance of RAPD-SCAR markers for the identification of Litchi chinensis Sonn. by improved RAPD amplification and molecular cloning. Electron J Biotechnol 18:35-39

Cho MS, Park DH, Namgung M, Ahn T-Y, Park DS (2015) Validation and application of a real-time PCR protocol for the specific detection and quantification of Clavibacter michiganensis subsp. sepedonicus in potato. Plant Pathol J 31:123-131

Gallelli A, Talocci S, Pilotti M, Loreti S (2014) Real-time and qualitative PCR for detecting Pseudomonas syringae pv. actinidiae isolates causing recent outbreaks of kiwifruit bacterial canker. Plant Pathol 63:264-276

Gardan L, Shafik H, Belouin S, Broch R, Grimont F, Grimont PAD (1999) DNA relatedness among the pathovars of Pseudomonas syringae and description of Pseudomonas tremae sp. nov. and Pseudomonas cannabina sp. nov. (ex Sutic and Dowson 1959). Int J Syst Bacteriol 49:469-478

Giaj Merlera G, Muñoz S, Coelho I, Cavaglieri LR, Torres AM, Reynoso MM (2015) Diversity of black Aspergilli isolated from raisins in Argentina: polyphasic approach to species identification and development of SCAR markers for Aspergillus ibericus. Int $\mathrm{J}$ Food Microbiol 210:92-101

Gilbert V, Legros F, Maraite H, Bultreys A (2009) Genetic analyses of Pseudomonas syringae isolates from Belgian fruit orchards reveal genetic variability and isolate-host relationships within the pathovar syringae, and help identify both races of the pathovar morsprunorum. Eur J Plant Pathol 124:199-218

Kałużna M, Ferrante P, Sobiczewski P, Scortichini M (2010a) Characterization and genetic diversity of Pseudomonas syringae isolates from stone fruits and hazelnut using repetitive-PCR and MLST. J Plant Pathol 92:781-787

Kałużna M, Puławska J, Sobiczewski P (2010b) The use of PCR melting profile for typing of Pseudomonas syringae isolates from stone fruit trees. Eur J Plant Pathol 126:437-443

Kałużna M, Janse JD, Young JM (2012) Detection and identification methods and new tests as used and developed in the framework of COST 873 for bacteria pathogenic to stone fruits and nuts Pseudomonas syringae pathovars. J Plant Pathol 94:S1.117-S1.126

Kałużna M, Puławska J, Waleron M, Sobiczewski P (2014) The genetic characterization of Xanthomonas arboricola pv. juglandis, the causal agent of walnut blight in Poland. Plant Pathol 63:1404-1416

Kerkoud M, Manceau C, Paulin JP (2002) Rapid diagnosis of Pseudomonas syringae pv. papulans, the causal agent of blister spot of apple, by polymerase chain reaction using specifically designed $h r p L$ gene primers. Phytopathology 92:10771083

King EO, Raney MK, Ward DE (1954) Two simple media for the demonstration of pyocianin and fluorescin. J Lab Clin Med 44:301-307

Lattore BA, Jones AL (1979) Pseudomonas morsprunorum, the cause of bacterial canker of sour cherry in Michigan and its epiphytic association with $P$. syringae. Phytopathology 69:335-339

Leibner-Ciszak J, Dobrowolska A, Krawczyk B, Kaszuba A, Staczek P (2010) Evaluation of a PCR melting profile method for intraspecies differentiation of Trichophyton rubrum and Trichophyton interdigitale. J Med Microbiol 59:185-192

Lelliott RA, Billing E, Hayward AC (1966) A determinative scheme for the fluorescent plant pathogenic Pseudomonads. J Appl Bacteriol 29:470-489

Lim SH, Kim JG, Kang HW (2009) Novel SCAR primers for specific and sensitive detection of Agrobacterium vitis strains. Microbiol Res $164: 451-460$

Liu Y, Li S, Zhu T, Shao B (2012) Specific DNA markers for detection of bacterial canker of kiwifruit in Sichuan, China. Afr J Microbiol Res 6:7512-7519

López M, Roselló M, Palacio-Bielsa A (2010) Diagnosis and detection of the main bacterial pathogens of stone fruit and almond. J Plant Pathol 92:S1.57-S1.66

Masny A, Płucienniczak A (2003) Ligation mediated PCR performed at low denaturation temperatures-PCR melting profiles. Nucl Acids Res 31(18), e114

Ménard M, Sutra L, Luisetti J, Prunier JP, Gardan L (2003) Pseudomonas syringae pv. avii (pv. nov.), the causal agent of bacterial canker of wild cherries (Prunus avium) in France. Eur J Plant Pathol 109:565576

Puławska J, Maes M, Deckers T, Sobiczewski P (1997) The influence of pesticide contamination on detection of epiphytic Erwinia amylovora using PCR. Meded Fac Landbouwkd Toegep Biol Wet Univ Gent 62:959-962

Ramakers C, Ruijter JM, Deprez RHL, Moorman AFM (2003) Assumption-free analysis of quantitative real-time polymerase chain reaction (PCR) data. Neurosci Lett 339:62-66

Renick LJ, Cogal AG, Sundin GW (2008) Phenotypic and genetic analysis of epiphytic Pseudomonas syringae populations from sweet cherry in Michigan. Plant Dis 92:372-378

Sangdee A, Natphosuk S, Srisathan A, Sangdee K (2013) Development of SCAR primers based on a repetitive DNA 
fingerprint for Escherichia coli detection. J Microbiol 51:3135

Saniewski M, Ueda J, Miyamoto K, Horbowicz M, Puchalski J (2006) Hormonal control of gummosis in Rosaceae. J Fruit Ornam Plant Res 14:137-144

Schaad NW, Cheong SS, Tamaki E, Hatziloukas E, Panopoulos NJ (1995) A combined biological and enzymatic amplification (BIOPCR) technique to detect Pseudomonas syringae pv. phaseolicola in bean seed extracts. Phytopathology 85:243-248

Schmidt O, Dujesiefken D, Stobbe H, Moreth U, Kehr R, Schröder T (2008) Pseudomonas syringae pv. aesculi associated with horse chestnut bleeding canker in Germany. For Pathol 38:124-128

Sorensen KN, Kim K-H, Takemoto JY (1998) PCR Detection of cyclic lipodepsinonapeptide-producing Pseudomonas syringae pv. syringae and similarity of strains. Appl Environ Microbiol 64: 226-230

Suslow TV, Schrooth MN, Isaka M (1982) Application of a rapid method for Gram differentiation of plant pathogenic and saprophytic bacteria without staining. Phytopathology 72:917-918

Ullrich M, Bereswill S, Volksch B, Fritsche W, Geider K (1993) Molecular characterization of field isolates of Pseudomonas syringae pv. syringae differing in coronatine production. J Gen Microbiol 139:1927-1937
Vicente JG, Roberts SJ (2007) Discrimination of Pseudomonas syringae isolates from sweet and wild cherry using rep-PCR. Eur J Plant Pathol 117:383-392

Vicente JG, Alves JP, Russell K, Roberts SJ (2004) Identification and discrimination of isolates from wild cherry in England. Eur J Plant Pathol 110:337-351

Waugh R, Bonar N, Baird E, Thomas B, Graner A, Hayes P, Powell W (1997) Homology of AFLP products in three mapping populations of barley. Mol Gen Genet 255:311-321

Weingart H, Völksch B (1997) Genetic fingerprinting of Pseudomonas syringae pathovars using ERIC-, REP-, and IS50-PCR. J Phytopathol 145:339-345

Young JM (2010) Taxonomy of Pseudomonas syringae. J Plant Pathol 92:5-14

Zasada AA, Formińska K, Wołkowicz T, Badell E, Guiso N (2014) The utility of the PCR melting profile technique for typing Corynebacterium diphtheriae isolates. Lett Appl Microbiol 59: 292-298

Zhang M, Chen WQ, Liu D, Liu TG, Gao L, Shu K (2012) Identification of a specific SCAR marker for detection of Tilletia foetida (Wall) Liro pathogen of wheat. Russ J Genet 48:663-666 